\title{
A Judgmental Reconstruction of Some of Professor Woleński's Logical and Philosophical Writings
}

\author{
Fabien Schang \\ Federal University of Goiás \\ Avenida Esperança, SN, Campus Samambaia - Conj. Itatiaia \\ Goiânia, 74690-900, Brasil \\ e-mail: schangfabien@gmail.com
}

\begin{abstract}
:
Roman Suszko said that "Obviously, any multiplication of logical values is a mad idea and, in fact, Łukasiewicz did not actualize it." The aim of the present paper is to qualify this 'obvious' statement through a number of logical and philosophical writings by Professor Jan Woleński, all focusing on the nature of truth-values and their multiple uses in philosophy. It results in a reconstruction of such an abstract object, doing justice to what Suszko held a 'mad' project within a generalized logic of judgments. Four main issues raised by Woleński will be considered to test the insightfulness of such generalized truth-values, namely: the principle of bivalence, the logic of scepticism, the coherence theory of truth, and nothingness. Keywords: bivalence, coherence, nothingness, partition semantics, scepticism, Jan Woleński.
\end{abstract}

\section{Introduction: Neither Frege, Nor Suszko (Therefore Lukasiewicz?)}

Suszko is known both for his eponymous acceptance of the 'Suszko Thesis', under which all logical systems whose consequence operator satisfies the criterion of structurality (or of extensionality) are bivalent systems, and for his rejection of the 'Frege's Axiom' (FA). We are going to focus on the latter, and more specifically on the different ways of opposing it. Suszko [27] is in some way opposed $\mathrm{FA}$, which consists of two sub-propositions $\left(\mathrm{FA}_{1}\right)-\left(\mathrm{FA}_{2}\right)$ :

$\mathrm{FA}_{1} \quad$ The referent of a sentence is its truth-value.

$\mathrm{FA}_{2}$ This truth-value is either the True or the False.

Suszko rejects $F_{1}$ and accepts $F_{2}$. According to him, sentences do not express truth-values but situations, and this explains why Suszko distinguishes identity from material equivalence or biconditional since the rejection of $\mathrm{FA}_{1}$ implies that two sentences may have the same truth-value without being identical. But there is another way to reject FA, by reasoning in reverse to Suszko and 
accepting $\mathrm{FA}_{1}$ while rejecting $\mathrm{FA}_{2}$. It is this position that we will associate with the name of Łukasiewicz and defend in this article, while seeking to justify it through several writings of Professor Woleński. It will thus be a matter of defending one direction of Polish logic against another, namely: many-valued logics of Łukasiewicz, as opposed to the 'non-Fregean' logic of Suszko.

Starting from a preliminary reflection on the meaning of the Principle of Contradiction (PC) and its analysis by Łukasiewicz, we will begin by distinguishing 'sentences' from 'propositions' and endorsing the many-valuedness entailed by the rejection of $\mathrm{FA}_{2}$ through a general logic of judgments. Then we will review a certain number of logical questions treated by Jan Woleński in the light of this logic of judgments: the Principle of Bivalence (PB), and its various definitions; the relationship between logic and scepticism, and the concept of duality; the relationship between coherence and truth, Tarski's T-scheme, and the relativity of the concept of truth; negation, and the philosophical notion of 'nothingness'. We hope that the logical framework resulting from our non-Suszkian rejection of FA will confirm and clarify certain reflections of Professor Woleński on all these matters. Last but not least, we will insist on a formal tool essential to metalogical reflection and which Woleński frequently uses in the articles treated here: the theory of opposition.

\section{Frege's Axiom and its Opponents}

FA is neither true nor false strictly speaking, so neither are what Suszko and Łukasiewicz said about it. It is rather necessary to think of this metalogical axiom in terms of explanatory virtue: which position with regard to FA is the most insightful, from an explanatory point of view?

FA relates to $\mathrm{PB}$, and Woleński [33], [34] pays attention to the ambiguous meaning of the last principle. In the first sense, bivalence means that any sentence is either true or false and thus corresponds to $\mathrm{FA}_{2}$. In a second sense, bivalence means that any sentence is true or is not. The difference between the two interpretations rests on the meaning of 'false'. ${ }^{1}$ A statement can be 'not true' without being 'false' from a many-valued point of view. In response to the many-valued logics promoted by Łukasiewicz, Suszko distinguishes between two kinds of truth-values: algebraic values, which are combinations of single truth-values such as 'true-and-false' or 'neither-true-nor-false'; logical values, which are sets of values intended to define logical consequence in terms of preserving truth. According to Suszko, there can only be two sets of logical values: designated values, which include truth; non-designated values, which exclude truth.

From a functional point of view, algebraic values therefore have no interest in providing no essential information to characterize a consequence relation in a given logical system. From an explanatory point of view, on the other hand, we will try to show in this article that the use of algebraic values is likely to shed light on philosophical concepts that a 'Suszkian' logic (without algebraic values) would be unable to explain. The introduction of 'non-Tarskian' or many-valued consequence relations [6], [12] was a first example of this kind, and we will try to see how a constructive approach to truth-values can modify our way to understand some logical and philosophical notions.

There is much more than one way of rejecting FA, if we consider this metalogical axiom as the conjunction of two logically independent propositions. The theory of oppositions can already help us to clarify the situation on this point, by considering FA as a binary proposition of type $\mathrm{FA}_{1} \wedge \mathrm{FA}_{2}$. With reference to the work of Piaget [13] and Blanché [2], we can affirm that any binary proposition, that is to say, any complex proposition including a binary logical operator, corresponds to a disjunction of four fundamental propositions which are called 'normal conjunctive forms'. Thus, a binary proposition of form $f(p, q)$ refers to four logical possibilities: (i) $p$ and $q$ are true together; (ii) $p$ is true and $q$ is false; (iii) $p$ is false and $q$ is true; (iv) $p$ and $q$ are false together. Frege's position on FA is that both FA ${ }_{1}$ and $\mathrm{FA}_{2}$ are true, while Suszko's position is that $\mathrm{FA}_{1}$ is false and $\mathrm{FA}_{2}$ is true. Suszko thus defends a 'counter-thesis', since his position is incompatible with that of Frege. But there is more than one 
conceivable counter-thesis: that which we will defend in the rest of this work, and which consists in saying that $\mathrm{FA}_{1}$ is true while $\mathrm{FA}_{2}$ is false.

Our position is almost the opposite of Suszko's. In fact, there are far more than two FA countertheses if one considers FA as one of sixteen possible combinations. Indeed, FA means that $\mathrm{FA}_{1}$ and $\mathrm{FA}_{2}$ are both true and thus represents a conjunctive proposition such that the two joint members must be true to satisfy the molecular proposition FA. Now fifteen other types of combinations are possible in the light of the theory of propositional conjunctive normal forms. If we use the symbols 1 and 0 to denote the satisfied and dissatisfied normal conjunctive forms, respectively, we obtain the following combinatorial list including the positions of Frege, Suszko, and Łukasiewicz.

\begin{tabular}{|l|c|c|c|c|}
\hline & $\mathrm{FA}_{1} \mathrm{FA}_{2}$ & $\mathrm{FA}_{1} \overline{\mathrm{FA}_{2}}$ & $\overline{\mathrm{FA}_{1}} \mathrm{FA}_{2}$ & $\overline{\mathrm{FA}_{1}} \overline{\mathrm{FA}_{2}}$ \\
\hline$(1)$ & 1 & 1 & 1 & 1 \\
\hline$(2)$ & 1 & 1 & 1 & 0 \\
\hline$(3)$ & 1 & 1 & 0 & 1 \\
\hline$(4)$ & 1 & 0 & 1 & 1 \\
\hline$(5)$ & 0 & 1 & 1 & 1 \\
\hline$(6)$ & 1 & 1 & 0 & 0 \\
\hline$(7)$ & 1 & 0 & 0 & 1 \\
\hline$(8)$ & 0 & 0 & 1 & 1 \\
\hline$(9)$ & 0 & 1 & 1 & 0 \\
\hline$(10)$ & 0 & 1 & 0 & 1 \\
\hline$(11)$ & 1 & 0 & 1 & 0 \\
\hline$(12)$ & 1 & 0 & 0 & 0 \\
\hline$(13)$ & 0 & 1 & 0 & 0 \\
\hline$(14)$ & 0 & 0 & 1 & 0 \\
\hline$(15)$ & 0 & 0 & 0 & 1 \\
\hline$(16)$ & 0 & 0 & 0 & 0 \\
\hline
\end{tabular}

Frege's position on FA thus corresponds to (12); that of Suszko corresponds to (14); the position that we will defend, finally, is that represented by (13). As for the thirteen remaining possibilities, their absence from the debate produced between Frege and Suszko is simply due to their non-exclusive form. Formula (2), for example, means an alternative between three possible attitudes: accept $\mathrm{FA}_{1}$ and accept $\mathrm{FA}_{2}$, or accept $\mathrm{FA}_{1}$ and reject $\mathrm{FA}_{2}$, or reject $\mathrm{FA}_{1}$ and $\mathrm{FA}_{2}$. In this sense, this formula symbolizes the union of the three incompatible positions defended by Frege, Suszko, and Lukasiewicz. We can also wonder about the meaning of the two limiting cases (1) and (16): the first consists in admitting all the possible positions about $\mathrm{FA}_{1}$ and $\mathrm{FA}_{2}$, while the second consists in admitting none. These kinds of acceptance can be described as 'second order' ones, because they relate to two propositions $\mathrm{FA}_{1}, \mathrm{FA}_{2}$ whose content is itself accepted or rejected by speakers. Thus Frege accepts (12) because he accepts $\mathrm{FA}_{1}$ and $\mathrm{FA}_{2}$, but he rejects the other fifteen formulas by rejecting at least one of the four possible attitudes. Suszko accepts (14) by accepting the attitude of rejecting $\mathrm{FA}_{1}$ and accepting $\mathrm{FA}_{2}$, but he rejects all other combinations. We accept (13) by accepting $\mathrm{FA}_{1}$ and rejecting $\mathrm{FA}_{2}$, while rejecting all other combinations of attitudes. The distinction between speech orders means that it makes sense to say that a speaker accept to accept, accepts to reject, rejects to accept or rejects to reject any proposition. It also means that there are several levels of discourse, in accordance with the well-established distinction between 'object language' and 'metalanguage'. This semantic abstraction will be important in the rest of the article, especially in relation to the issues of scepticism and the concept of nothingness. 
About FA, the presentation of the 16 attitudes in the form of a series of Boolean values 1-0 makes it possible to introduce the theory of oppositions in our present debate. Let us make a first distinction between an antithesis and a counter thesis, which are two logical relations established between propositions or 'theses'. Let $\operatorname{AT}(a, b)$ symbolizing the antithesis relation between theses $a$ and $b$, and let $\mathrm{CT}(a, b)$ for the counter thesis relation between $a$ and $b$. We can then explain these two relations as follows:

- the antithesis $\operatorname{AT}(a, b)$ means $a$ is contradictory with respect to $b$ and consists in adopting an attitude opposite to it, turning any acceptance of $b$ - symbolized by the value 1 - into a rejection - symbolized by the value 0 (and vice versa);

- the counter-thesis $\mathrm{CT}(a, b)$ means that thesis a is simply incompatible with the thesis $b$, turning any attitude of acceptance of $b$ into an attitude of rejection (but the converse need not be the case).

The three positions of Frege, Suszko and Łukasiewicz therefore have only one possible antithesis: $\operatorname{AT}(12)=(5), \operatorname{AT}(13)=(4)$, and $\operatorname{AT}(14)=(3)$. On the other hand, there are as many counter theses to each of these attitudes as there are distinct possibilities of rejecting what is accepted there. In other words, any counter thesis is a thesis which does not accept what the initial thesis accepts but which can reject what the initial thesis rejects. There are thus a total of six counter theses available for the three attitudes of Frege, Suszko and Łukasiewicz:

$$
\begin{aligned}
& \mathrm{CT}(12)=\{(8),(9),(10),(13),(14),(15)\} \\
& \mathrm{CT}(13)=\{(7),(8),(11),(12),(14),(15)\} \\
& \mathrm{CT}(14)=\{(6),(7),(10),(12),(13),(15)\}
\end{aligned}
$$

Since most counter theses are unions of possible attitudes, they have no philosophical relevance to the singular positions (12), (13) and (14). But this first allusion to the theory of oppositions allows at least to sketch a first type of main opposition between three of the sixteen attitudes above: a triad of contraries opposing FA (12), the criticism of his first proposition by Suszko (13), and Łukasiewicz's critique of his second proposition (14).

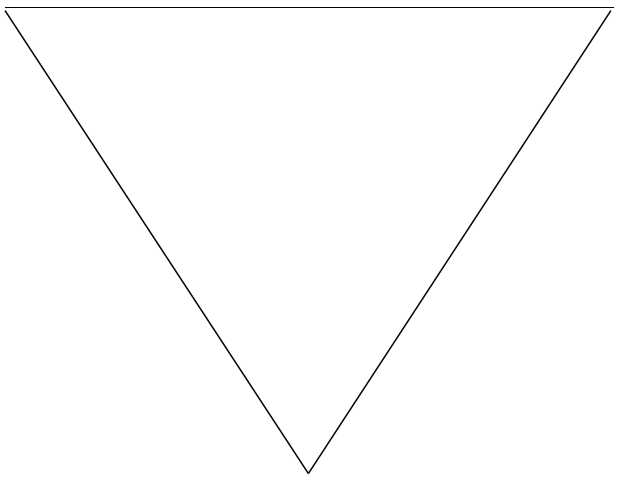

(14)

The point is now to examine the content of FA and its two main features, which are functionality (through $\mathrm{FA}_{1}$ ) and bivalence (through $\mathrm{FA}_{2}$ ). 


\section{Pragmatic Contradiction}

In his attempt to prove one of the fundamental principles of 'classical' logic, i.e. PC, Jan Łukasiewicz [10] has shown not only that it is unprovable but that it also rests on three distinct readings: an 'ontological' reading, by virtue of which PC says that it is impossible for the same object to have a property and not to have it at the same time; a 'logical' reading, whereby PC means that a proposition cannot be true and false at the same time; a 'psychological' reading, by virtue of which PC says that one cannot believe and not believe in the same judgment. The formulation of the logical principle divides those who present it in terms of the truth-value of a proposition and those who formulate it in terms of a proposition and its negation. Woleński [34], [35] will emphasize the two aspects of PC: a logical or 'object language' version, of form

$$
\sim(p \wedge \sim p)
$$

and a metalogical version, of form

$$
v(p)=T \text { or } v(p)=F
$$

Although Łukasiewicz quickly neglected the psychological version of PC, for the reason that subjects often hold inconsistent beliefs, ${ }^{2}$ the example given in Łukasiewicz [10] evokes the singular case of religious belief in Trinity: it would be possible according to believe that God is and is not the same individual as Father, Son or Holy Spirit, on the occasion of a religious experience that any good Christian would be able to experience within the framework of his faith. Although the empirical objection to PC in its psychological version could be taken seriously, Łukasiewicz was more interested in the ontological and logical foundations of the principle. These do not seem to be more solid than the psychological version, especially since they are based on an ambiguous vocabulary. The ontological principle speaks of objects and refers to facts or states of affairs obtaining in the world. The logical principle speaks sometimes of truth-values sometimes of affirmation and negation, but both cannot make sense without relying on a correspondence theory of truth where facts make a proposition 'true'. As for the 'proposition', it designates from Aristotle onwards any sentence belonging to the grammatical case of indicative and whose linguistic function is to tell something about the world, viz. what 'the case' is. ${ }^{3}$

We will not go into the details of this discussion on the foundations of PC, since it goes beyond our central point. We simply observe the following few complications. First, the correspondence theory of truth poses a problem on the conditions of falsity of a proposition: either the existence of a fact which contradicts the proposition is necessary to make it false, or the simple absence of fact to make the proposition true entails its falsity. The choice of the correct definition of falsity is important here, since it relates to the universality of PB as well as the validity of PEM. Second, the psychological version of PC makes use of concepts to which everyone else can be reduced. A proposition is true if it corresponds to an objective fact, by virtue of the correspondence theory; but in the absence of sufficient means to prove the existence of such a fact, what is a 'proposition' if not the public expression of a belief expressed by a judgment? On the other hand, there is a common confusion between two pairs of concepts, namely: affirmation and negation, by distinction of truth and falsehood. We know that a proposition can be negative and true, as in 'Poland is not a planet', or affirmative and false, as in 'Poland is a planet'. But what is a judgment, if not the use by a speaker of a proposition in order to sincerely express his own opinion on what 'the case' is? Frege's distinction between a judgeable content and a judgment may be justified, but it seems useless if the correspondence theory of truth is unable to afford the conditions of correspondence with a 'fact' in an incontestable and definitive 
manner. We know that this theory must face theoretical difficulties, and that two other competing theories of truth face it: truth as coherence, and truth as consensus. Another radical solution could remedy these philosophical difficulties: the 'minimalist' or 'redundant' theory of truth, according to which the occurrence of the concept of truth in a sentence is useless because it does not add any substantial information to it. This last point of view will come back in this article, when questioning the application of Tarski's T-schema.

For want of conclusive answer about the foundations and the validity of PC, let us now try to defend an alternative view and to assess its explanatory virtues: the pragmatic (or illocutionary) interpretation of PC, which extends what Łukasiewicz called the 'psychological' version while eliminating its psychological connotation.

We will thus start by assuming that the concepts of truth and falsehood, but also the concepts of affirmation and negation are nothing but items of a general theory of speech acts, in which it is not the proposition but the judgment (or statement) which constitutes the primary vehicle of meaning. According to this approach, every statement has the logical form $\mathrm{F}(p)$ and includes two elements: a sentential content $p$, which corresponds to Frege's 'judgeable content'; an illocutionary force F, which carries the purpose that the sentential content is supposed to express in a given dialogue. Since everyday language has the defect of using the same expression for sentential contents, e.g. 'The door is closed', and for their 'assertive' use, let us replace the first with a propositional concept such as 'The door's being closed'. The assertive use of this concept thus yields the speech act 'The door is closed', but there are other uses of the same concept such as the act of questioning, 'Is the door closed?', the act of giving an order, 'Be the door closed!', etc. In the case of the logical principles that concern us here, we can apply this theory of speech acts to lead to some illocutionary interpretations of logical notions.

Affirmation and negation are two types of assertive acts intended to indicate to an interlocutor what 'the case' is, and one of the central points concerns the question of whether these two acts are interdependent or logically independent from each other. 'Truth' and 'falsehood' can be reduced in this theory to the speaker's ontological commitments: to say of a proposition that it is true means that the propositional content it expresses fits to one state of the world; to say that it is false means that it does not fit. There is no difference between the truth of a proposition and the recognition of its truth by the speaker, within the framework of this theory. If this is the case, the problem is to know if this speaker can act other than by recognizing the truth of what a statement expresses. There can be but one judgment, according to Frege: either we recognize the truth of a statement, and we express the latter by 'The door is closed'; either we do not recognize it, and we express its falsity indirectly by 'The door is not closed'. But what if the speaker does not know whether the door is closed?

Von Wright proposes a grammatical test to know if a statement is a 'proposition': "A grammatically well-formed sentence expresses a proposition if, and only if, the sentence which we get by prefixing to it the phrase 'it is true that' is also well-formed" $[29, \text { p. 6. }]^{3}$ For example, 'It is true that the door is closed' is well-formed and, therefore, the sentence 'The door is closed' is a proposition; on the other hand, that 'It is true that close the door!' is an ill-formed sentence entails that 'Close the door!' is not a proposition. Von Wright's analysis does not just corroborate the theory of speech acts anticipated by Aristotle and established by Searle; it will also justify the existence of propositions which are neither true nor false, such as normative propositions like 'The length of the standard meter in Paris is 1 meter' ${ }^{4}$ or metaphysical propositions like 'To be is to be perceived'. A proposition can therefore be neither true nor false while belonging to the class of assertive acts. We will examine in the following the consequences of this result on several issues of logic, all scrutinized by Woleński.

\section{Pragmatic Bivalence}

Woleński [34] presents $\mathrm{PB}$ as the conjunction of two metalogical propositions. The first is a metalogical version of PEM: 
(1) Every sentence is either true or false.

The second is a metalogical version of PC:

(2) No sentence is both true and false.

The combination of (1) and (2) relates to four forms of metalogical judgments, either affirmative or negative. By taking up the idea of von Wright [29], i.e. prefixing arbitrary sentences $p$ by a truth operator T, we thus obtain four types of judgments: T $p$ for 'It is true that $p$ ' and Fp for 'It is false that $p$ ', which are affirmative judgments; $\sim \mathrm{T} p$ for 'It is not true that $\mathrm{p}$ ' and $\sim \mathrm{F} p$ for 'It is not false that $p$ ', which are negative judgments. As usual, Woleński [34] then proposes a logical hexagon, (S2), to represent the logical relationships between these four judgments. The advantage of this hexagon is that it relativizes PB by depicting it as a non-tautological vertex (see below).

The top vertex of (S2) expresses the affirmative clause (1) of PB, while its contradictory at the bottom vertex symbolizes the negation of (1). Consequently, anyone who subscribes to PB cannot think in terms of this hexagon without accepting two situations incompatible with bivalence: on the one hand, the possibility for a sentence not to be true without being false $(\sim \mathrm{T} p$ does not entail $\mathrm{F} p)$ and not to be false without being true $(\sim \mathrm{F} p$ does not entail $\mathrm{T} p)$; on the other hand, there is the possibility for a sentence to be neither true nor false $(\sim \mathrm{T} p \& \sim \mathrm{F} p)$. At the same time, (S2) does not include the case of 'true contradictory' sentences, or dialetheias, of form T $p \wedge \mathrm{F} p$. This sentence is incompatible with (S2), since $\mathrm{T} p$ and $\mathrm{F} p$ are contrary to it $(\sim(\mathrm{T} p \wedge \mathrm{F} p)$ holds in (S2)). However, just as what Woleński calls 'neutralities' [34, p. 103] is possible in (S2) and consists in rejecting the affirmative clause of PB, an opponent of PB must be able to accept the possibility of 'dialetheias' and to reject (2) into a nonbivalent logic. Although Woleński doubts the intuitive meaning of dialetheias by claiming that "I did not find any natural matrix semantics for paraconsistent logic" [34, p. 12], it is nevertheless possible to justify their existence, in particular by proceeding with what von Wright [29] describes as a shift of meaning in the concept of truth.

Referring to the example of drizzle as a 'transition zone' between rainy and dry weather, von Wright explains that this situation can be logically analyzed in two distinct ways: either as a situation where it is neither totally the case that it rains nor totally the case that it does not rain, insofar as drops of water still fall from the sky; either as a situation where it is still raining and already the case it is not raining anymore, insofar as simple drops of water are still rain and already a situation of no rain. This means that one and the same situation can be considered either as a case of neutrality or as a case of dialetheia, but not by virtue of the same interpretation of what 'the case' is or truth:

It should be observed that a conceptual shift has now taken place in the notion of truth. It is not the same sense of 'true' in which we say that is neither raining nor not-raining and say that it is both raining and not-raining in the zone of transition. We could call the former a strict sense of 'true' and the latter a liberal or more lax sense of truth [29, p. 13]. ${ }^{5}$ 
(S2)

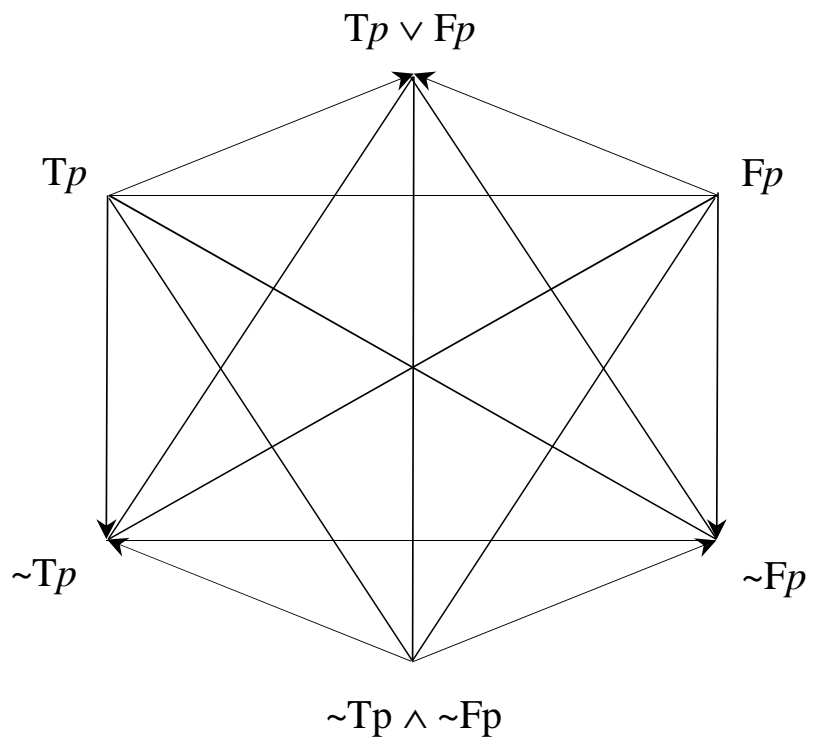

The difference between the two interpretations of the concept of truth appears clearly in the below diagram by Von Wright [29], [30], where the 'gappy' and 'glutty' propositions do not correspond to the same 'logical zone' and are expressed respectively by a strict operator $\mathrm{T}$ and a liberal operator $\mathrm{T}^{\prime}$.

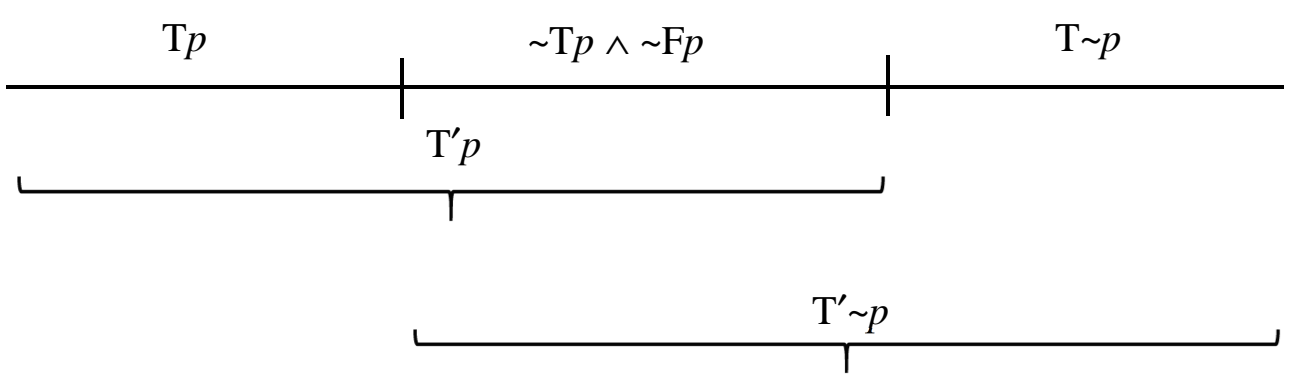

Woleński's hexagon (S2) is therefore only a fragment of non-bivalent logical systems, and we must take into account the two interpretations of the concept of truth in order to establish a set of exhaustive relationships between all possible judgments of truth and falsehood.

For this purpose, we propose in the following a reconstruction of $\mathrm{PB}$ in the form of four independent clauses. Indeed, (1) and (2) above are complex formulas including two atomic sentences. (1) can be divided into two conditional sub-sentences or clauses implying an affirmative consequent:

(1.1) If $p$ is not false, then $p$ is true.

(1.2) If $p$ is not true, then $p$ is false.

Similarly, (2) can be divided into two clauses implying a negative condition:

(2.1) If $p$ is true, then $p$ is not false. 
(2.2) If $p$ is false, then $p$ is not true.

These four clauses are of a metalogical order, so they are no material conditionals; rather, they represent procedural constraints imposed on affirmative judgments, such that it is not allowed to assign a certain algebraic value to a sentence without rejecting another at the same time. The general form of $\mathrm{PB}$ is a clause like

\section{If $p$ is $X$, then $p$ is not $Y$}

and can be interpreted as a mapping, that is, a homomorphism between a domain of values and a counter-domain:

$$
X \mapsto Y
$$

where $X$ and $Y$ denote arbitrary truth-values within a given domain.

An important question is: can a rational agent subscribe to one or the other of these clauses without admitting the others, so that each of them would be considered logically independent of all the others? A reconstruction of PB was recently proposed in Schang [25], where this last principle is represented as the combination of four statement operators $\left[\mathrm{A}_{i}\right] p$, meaning 'It is the case that $p$ ' or 'It is true that $p$ '. Assertion corresponds to the assertive speech act by which the agent accepts the truth of $p$, in accordance with our pragmatic interpretation of the concept of truth. This operator is also able to translate the two distinct meanings of the concept of truth expressed by von Wright, while preserving the idea accepted since Frege according to which affirming the falsehood of a sentence is affirming the truth of its sentential negation,

$$
\mathrm{F} p \Leftrightarrow \mathrm{T} \sim p
$$

In addition, we will see that these two 'truth-operators' are only two particular cases within a general logic of acts of acceptance and rejection. ${ }^{6}$ On the basis of the partial statement operator $\left[\mathrm{A}_{i}\right], \mathrm{PB}$ can be reconstructed as a set of four types of operators applied to truth-values and translating the four clauses $(1.1)-(2.2)$ as follows:

(1.3) $\left[\mathrm{A}_{1}\right] p: \bar{T} \mapsto \bar{F}$

(1.4) $\left[\mathrm{A}_{2}\right] p: F \mapsto \bar{T}$

(1.1) $\left[\mathrm{A}_{3}\right] p: \bar{T} \mapsto F$

(1.2) $\left[\mathrm{A}_{4}\right] p: \bar{F} \mapsto T$

These operators are 'partial', because they transform only some of (but not all) values of the initial domain: if $p$ is $X$, then $p$ is not $Y$; but if $p$ is not $\mathrm{X}$ in the initial state of the domain of values, then nothing happens, i.e. no transformation occurs in the final state of the counter-domain. ${ }^{7}$ The 'positive' values $T$ and $F$ denote acts of acceptance (of truth and falsehood), as opposed to the 'negative' values which denote acts of rejection (of truth or falsehood). The independence of negative values is explained by our pragmatic interpretation of truth-values and by the primacy of acts of judgment over the assignments of these truth-values, which are only expressions of propositional attitudes towards a primary truth-value: the True. Von Wright explains this point as follows:

How many truth-values are there? Shall we say there are two: truth, and falsehood? Or count the gaps and overlaps too as truth-values and say there are four in all? As will be seen later, we shall make use of a 4-valued matrix. But since all four values are definable in 
terms of truth and negation, it would also be possible to say that basically there is only one 'truth-value', viz. true [29, p. 314]. ${ }^{8}$

Moreover, 'classical' logic seems 'simpler' than four-valued systems insofar as it makes uses of only two truth-values. But from our pragmatic point of view, it is less simple because it imposes more constraints on the acts of acceptance and rejection. The Bivalentist equates the 'false' with any statement that is not true, so that rejecting the truth of a statement is sufficient to accept its falsity from his point of view. However, this condition is not imposed on a speaker whose rationality does not include the operator $\left[\mathrm{A}_{3}\right]$.

As a matter of fact, there is a set of $2^{m-1}$ possible acceptance operators within a domain of $m$ truth-values, knowing that this domain of values can increase from $2^{n}=m$ to $2^{n+1}$ elements. ${ }^{9}$ Woleński [34] pointed out that any domain of values including $m<2$ truth-values is trivial and unable to satisfy the properties of the Tarskian consequence operator. In the present case, let us consider the particular domain of values in which the $m=4$ truth-values are the true $T$, the non-true $\bar{T}$, the false $F$, and the non-false $\bar{F}$. The $2^{4}-1=15$ acceptance operators available in this domain are the following, where the product $\oplus$ consists in adding a variable number of restrictions on judgments.

$$
\begin{gathered}
{\left[\mathrm{A}_{1}\right] p: T \mapsto \bar{F}} \\
{\left[\mathrm{~A}_{2}\right] p: F \mapsto \bar{T}} \\
{\left[\mathrm{~A}_{3}\right] p: \bar{T} \mapsto F} \\
{\left[\mathrm{~A}_{4}\right] p: \bar{F} \mapsto T} \\
{\left[\mathrm{~A}_{5}\right] p=\left(\left[\mathrm{A}_{1}\right] \oplus\left[\mathrm{A}_{2}\right]\right) p: T \mapsto \bar{F} \oplus F \mapsto \bar{T}} \\
{\left[\mathrm{~A}_{6}\right] p=\left(\left[\mathrm{A}_{1}\right] \oplus\left[\mathrm{A}_{3}\right]\right) p: T \mapsto \bar{F} \oplus \bar{T} \mapsto F} \\
{\left[\mathrm{~A}_{7}\right] p=\left(\left[\mathrm{A}_{1}\right] \oplus\left[\mathrm{A}_{4}\right]\right) p: T \mapsto \bar{F} \oplus \bar{F} \mapsto T} \\
{\left[\mathrm{~A}_{8}\right] p=\left(\left[\mathrm{A}_{2}\right] \oplus\left[\mathrm{A}_{3}\right]\right) p: F \mapsto \bar{T} \oplus \bar{T} \mapsto F} \\
{\left[\mathrm{~A}_{9}\right] p=\left(\left[\mathrm{A}_{2}\right] \oplus\left[\mathrm{A}_{4}\right]\right) p: F \mapsto \bar{T} \oplus \bar{F} \mapsto T} \\
{\left[\mathrm{~A}_{10}\right] p=\left(\left[\mathrm{A}_{3}\right] \oplus\left[\mathrm{A}_{4}\right]\right) p: \bar{T} \mapsto F \oplus \bar{F} \mapsto T} \\
{\left[\mathrm{~A}_{11}\right] p=\left(\left[\mathrm{A}_{1}\right] \oplus\left[\mathrm{A}_{2}\right] \oplus\left[\mathrm{A}_{3}\right]\right) p: T \mapsto \bar{F} \oplus F \mapsto \bar{T} \oplus \bar{T} \mapsto F} \\
{\left[\mathrm{~A}_{12}\right] p=\left(\left[\mathrm{A}_{1}\right] \oplus\left[\mathrm{A}_{2}\right] \oplus\left[\mathrm{A}_{4}\right]\right) p: T \mapsto \bar{F} \oplus F \mapsto \bar{T} \oplus \bar{F} \mapsto T} \\
{\left[\mathrm{~A}_{14}\right] p=\left(\left[\mathrm{A}_{2}\right] \oplus\left[\mathrm{A}_{3}\right] \oplus\left[\mathrm{A}_{4}\right]\right) p: F \mapsto \bar{T} \oplus \bar{T} \mapsto F \oplus \bar{F} \mapsto T} \\
{\left[\mathrm{~A}_{15}\right] p=\left(\left[\mathrm{A}_{1}\right] \oplus\left[\mathrm{A}_{2}\right] \oplus\left[\mathrm{A}_{3}\right]\right) p: T \mapsto \bar{F} \oplus F \mapsto \bar{T} \oplus \bar{T} \mapsto F \oplus \bar{F} \mapsto T}
\end{gathered}
$$

Von Wright's strong truth-operator $\mathrm{T}$ corresponds to the acceptance operator $\left[\mathrm{A}_{6}\right]$ : it consists in judging as true every sentence that is not held false, and as false every sentence that is not held true.

$$
\mathrm{T} p=\left[\mathrm{A}_{6}\right] p: T \mapsto \bar{F} \oplus \bar{T} \mapsto F
$$

The operator $\mathrm{T}$ thus obeys two of the four clauses of $\mathrm{PB}$, i.e. (1.1) and (2.1). The weak truth-operator $\mathrm{T}^{\prime}$ corresponds to another acceptance operator, $\left[\mathrm{A}_{9}\right]$ :

$$
\mathrm{T}^{\prime} p=\left[\mathrm{A}_{9}\right] p: F \mapsto \bar{T} \oplus \bar{F} \mapsto T
$$


according to which any sentence that is held false is a sentence that is not held true and any sentence that is not held false is a sentence that is held true. Hence the operator $T^{\prime}$ does not obey the same clauses of PB as the operator T, since the latter satisfies (1.2) and (2.2).

By interpreting pragmatically the four truth-values as an ordered pair of accepted or rejected truth-values, we thus obtain the translations $B=11, T=10, F=01$ and $N=00$ and the following matrices characterizing the 'strict' and 'liberal' truth-operators.

\begin{tabular}{|l|c|c|}
\hline$p$ & $\mathrm{~T} p$ & $\mathrm{~T}^{\prime} p$ \\
\hline 11 & 10 & 01 \\
\hline 10 & 10 & 10 \\
\hline 01 & 01 & 01 \\
\hline 00 & 01 & 10 \\
\hline
\end{tabular}

The third metalogical operator of von Wright $[29,30]$, the operator of falsity Fp, does not occur among the operators $\left[\mathrm{A}_{1}\right]-\left[\mathrm{A}_{15}\right]$ because its definition is essentially based on a type of information irreducible to the terms of $\mathrm{PB}$. It essentially involves sentential negation, knowing that $\mathrm{F} p \Leftrightarrow \mathrm{T} \sim p$. It is this negation that we will explain now, in pragmatic terms of rejection.

The second type of judgment, viz. rejection $[\mathrm{N}]$, is independent of the acceptance operator $\left[\mathrm{A}_{i}\right]$. The latter imposes restrictions on 'positive' judgments of type ' $p$ is $X$ ', while rejection corresponds to the class of operators imposing constraints on 'negative' judgments of type ' $p$ is not $X$ '. The general form of the rejection operator is

if $p$ is $X$, then $p$ is not $X$,

that is, a mapping of the general form

$$
X \mapsto \bar{X}
$$

which differs from the operator of acceptance by the identity of the transformed truth-value of the counter-domain. Due to the procedural similarity in the mappings of affirmative and negative judgments, there may be as many separate rejection operators $\left[\mathrm{N}_{i}\right]$ as there are acceptance operators $\left[\mathrm{A}_{i}\right]$. To build such a rejection operator, it suffices to repeat the pattern of $\left[\mathrm{A}_{i}\right]$ whilst replacing the truth-value of the counter-domain $Y$ by the value $X$ of the initial domain.

'Classical' negation can be understood in two distinct ways, in this general logic of acceptance and rejection: either as that which turns the true into false and the false into true, by virtue of PB; either as that which turns the true into non-true and the false into non-false, independently of PB. Suszko's acceptance of the clause $\mathrm{FA}_{2}$ consists in treating the two explanations above as equivalent: the algebraic 'not-true' is a logical 'false', in the sense that it expresses a not-designated value $W D$ which excludes the algebraic 'true'; the algebraic 'not-false' is a logical 'true', in the sense that it expresses a designated value $\mathrm{D}$ which includes the algebraic 'true'. Now there are rejection operators $\left[\mathrm{N}_{i}\right]$ which do not turn any designated value into an undesignated value, and vice versa. Taking the example of the particular operator $\left[\mathrm{N}_{2}\right]$,

$$
\left[\mathrm{N}_{2}\right] p: F \mapsto \bar{F}
$$

this case of partial rejection is such that the initial truth of $p$ is left unchanged in the final counterdomain. It is therefore necessary to specify the formulation of 'classical' negation $\left[\mathrm{N}_{\mathrm{C}}\right]$ as any rejection operator which turns the designated or 'true' into non-designated or 'non-true', i,e., 


$$
\left\{\left[\mathrm{N}_{\mathrm{C}}\right] p \mid\left[\mathrm{N}_{\mathrm{C}}\right] p \supseteq T \mapsto \bar{T}\right\}
$$

However, 'classical' negation behaves traditionally as a 'total' function that transforms all the truthvalues of the initial domain; thus, its pragmatic counterpart will be here the rejection operator $\left[\mathrm{N}_{15}\right]$ :

$$
\left[\mathrm{N}_{15}\right] p=\left(\left[\mathrm{A}_{1}\right] \oplus\left[\mathrm{A}_{2}\right] \oplus\left[\mathrm{A}_{3}\right] \oplus\left[\mathrm{A}_{4}\right]\right) p: T \mapsto \bar{T} \oplus F \mapsto \bar{F} \oplus \bar{T} \mapsto T \oplus \bar{F} \mapsto F
$$

We will call this total negation a 'Boolean' negation, rather than a 'classic' negation which designates the use of negation within the classical logic system.

Falsehood, on the other hand, is a 'mixed' operator that associates the operator of truth with a sentential negation. The negation in question in the operator of falsehood $\mathrm{F} p=\mathrm{T} \sim p$ is what von Wright [29] describes as internal or strong negation ('it is the case that not'), as opposed to external or weak negation or weak ('it is not the case that'). Internal negation is not prefixed to the operator T, but to the sentential content $p$. Now the rejection operators $\left[\mathrm{N}_{i}\right]$ are not able to explain this negation, because they are only constructors of external negations. Strong negation stands 'halfway' between the operators of acceptance and rejection, insofar as it consists in accepting the negation of a given statement and not in simply denying this statement. To represent strong negation, we need a third type of mapping which is neither acceptance nor rejection but a 'fusion' of the two basic judgment operators. This hybrid operator can characterize internal negation (or 'Morganian') as follows:

$$
\left[\mathrm{AN}_{i}\right] p: X \mapsto \overline{\bar{Y}}=X \mapsto Y
$$

which can be paraphrased as 'rejected acceptance' or 'accepted rejection' ${ }^{\text {'10 }}$ and whose traditional characterization corresponds to total negation $\left[\mathrm{AN}_{15}\right]$ :

$$
\left[\mathrm{AN}_{15}\right] p: T \mapsto F \oplus F \mapsto T \oplus \bar{T} \mapsto \bar{F} \oplus \bar{F} \mapsto \bar{T}
$$

It is therefore possible to translate the operator of falsity $\mathrm{F}=\mathrm{T} \sim p$ as the expression of a particular affirmation

$$
\mathrm{F} p=\mathrm{T}\left[\mathrm{NA}_{15}\right] p=\left[\mathrm{A}_{9}\right]\left[\mathrm{NA}_{15}\right] p,
$$

and weak truth $\mathrm{T}^{\prime} p=\sim \mathrm{F} p$ as the total rejection of the falsity-operator:

$$
\mathrm{T}^{\prime} p=\sim \mathrm{F} p=\left[\mathrm{N}_{15}\right]\left[\mathrm{A}_{9}\right]\left[\mathrm{NA}_{15}\right] p .
$$

We obtain the characteristic matrices of the operators $\mathrm{F}$ and $\mathrm{T}^{\prime}$ on the basis of their above pragmatic reconstruction:

\begin{tabular}{|l|c|c|c|}
\hline$p$ & {$\left[\mathrm{NA}_{15}\right] p$} & {$\left[\mathrm{~A}_{9}\right]\left[\mathrm{NA}_{15}\right] p$} & {$\left[\mathrm{~N}_{15}\right]\left[\mathrm{A}_{9}\right]\left[\mathrm{NA}_{15}\right] p$} \\
\hline 11 & 11 & 10 & 01 \\
\hline 10 & 01 & 01 & 10 \\
\hline 01 & 10 & 10 & 01 \\
\hline 00 & 00 & 01 & 10 \\
\hline
\end{tabular}

The set of operators of acceptance, rejection, and the fusion of both constitutes a generalized logical framework, $\mathrm{AR}_{4[\mathrm{O} i]}{ }^{11}$, which is a set of 4-valued systems composed of the usual logical constants 
(conjunction, disjunction, conditional), pragmatic operators $\left[\mathrm{O}_{i}\right]=\left\{\left[\mathrm{A}_{i}\right],\left[\mathrm{N}_{i}\right]\right\}$, and in which the sentential variables (atomic or molecular) are always preceded by a judgment operator $\left[\mathrm{O}_{i}\right] .{ }^{12} \mathrm{An}$ extension of this framework to $n$-valent systems corresponds to the universal logical framework $\mathrm{AR}_{4[\mathrm{O} i]}$, but our reflection will be limited to the 4-valued domain in the following.

It is already possible to reconstruct four types of logical systems in $\mathrm{AR}_{4[\mathrm{O} i]}$, by means of the two operators of acceptance and rejection and the two negations, external (or 'Boolean') and internal (or 'Morganian'). These three categories are distinguished by their attitude towards two main metalogical properties: completeness (semantics), and consistency. The first property corresponds to the clauses $(2.1)-(2.2)$ of $\mathrm{PB}$, and the second property corresponds to the clauses $(1.1)-(1.2)$.

The first category of logical systems translatable in terms of $\left[\mathrm{A}_{i}\right]$ is the set of 'classical' systems, that is to say, complete and consistent. They correspond to von Wright's logic CL. Although there is traditionally only one single logic system called 'classical', there can exist more than one if we interpret the term 'classical' in the sense of Suszki's bivaluation: every sentence receives only one truth-value, $T$ or $F$, in accordance with the second clause $\mathrm{FA}_{2}$ of Frege's Axiom. The class of 'classical' systems thus corresponds to the class of logical systems whose characteristic operators $\left[\mathrm{A}_{i}\right]$ produce only two algebraic values: those which von Wright calls 'unilateral' truth, 10 (true and non-false) and 'unilateral' falsehood, 01 (false and not-true). It has been shown in Schang [25] that several $\left[\mathrm{A}_{i}\right]$ are consistency-and-completeness-forming operators in that they form 'unilateral' judgments: $\left[\mathrm{A}_{6}\right],\left[\mathrm{A}_{7}\right]$, $\left[\mathrm{A}_{8}\right]$ and $\left[\mathrm{A}_{9}\right]$, whose common feature is to satisfy one and only one clause of consistency and completeness: $(1.1)-(2.1),(1.1)-(2.2),(1.2)-(2.1)$, or $(1.2)-(2.2)$. The matrices below show the 'classic' behavior of rational agents subscribing to one or other of the bivalent restrictions on truthvalues:

\begin{tabular}{|l|c|c|c|c|}
\hline$p$ & {$\left[\mathrm{~A}_{6}\right] p$} & {$\left[\mathrm{~A}_{7}\right] p$} & {$\left[\mathrm{~A}_{8}\right] p$} & {$\left[\mathrm{~A}_{9}\right] p$} \\
\hline 11 & 10 & 10 & 01 & 01 \\
\hline 10 & 10 & 10 & 10 & 10 \\
\hline 01 & 01 & 01 & 01 & 01 \\
\hline 00 & 01 & 10 & 01 & 10 \\
\hline
\end{tabular}

The second category of logical systems is the set of complete and non-consistent systems, viz. 'paraconsistent'. They correspond to von Wright's logic T'L. Each of these systems satisfies one completeness clause among (1) and (2), but none of the two consistency clauses (3) - (4). There are again several ways of obtaining these conditions in $\mathrm{AR}_{4[\mathrm{O} i]}$, hence several paraconsistency-forming operators of acceptance: $\left[\mathrm{A}_{3}\right],\left[\mathrm{A}_{4}\right],\left[\mathrm{A}_{10}\right],\left[\mathrm{A}_{13}\right],\left[\mathrm{A}_{14}\right]$, whose common feature is to accept the 'glutty' or 'overlapping' algebraic value $B=11$.

\begin{tabular}{|l|c|c|c|c|c|}
\hline$p$ & {$\left[\mathrm{~A}_{3}\right] p$} & {$\left[\mathrm{~A}_{4}\right] p$} & {$\left[\mathrm{~A}_{10}\right] p$} & {$\left[\mathrm{~A}_{13}\right] p$} & {$\left[\mathrm{~A}_{14}\right] p$} \\
\hline 11 & 11 & 11 & 11 & 11 & 01 \\
\hline 10 & 10 & 10 & 10 & 10 & 10 \\
\hline 01 & 01 & 01 & 01 & 01 & 01 \\
\hline 00 & 01 & 10 & 11 & 11 & 11 \\
\hline
\end{tabular}

The third category of logical systems is the class of non-complete and consistent systems, or 'paracomplete'. They correspond to von Wright' TL logic. Each of these systems satisfies one consistency clause among (2.1) and (2.2), but none of the two completeness clauses (1.1) - (1.2). The paracompleteness-forming operators of acceptance admit the 'bilateral' incomplete value $N=00$ and are the following: $\left[\mathrm{A}_{1}\right],\left[\mathrm{A}_{2}\right],\left[\mathrm{A}_{5}\right],\left[\mathrm{A}_{11}\right],\left[\mathrm{A}_{12}\right]$. 


\begin{tabular}{|l|c|c|c|c|c|}
\hline$p$ & {$\left[\mathrm{~A}_{1}\right] p$} & {$\left[\mathrm{~A}_{2}\right] p$} & {$\left[\mathrm{~A}_{5}\right] p$} & {$\left[\mathrm{~A}_{11}\right] p$} & {$\left[\mathrm{~A}_{12}\right] p$} \\
\hline 11 & 10 & 01 & 00 & 00 & 00 \\
\hline 10 & 10 & 10 & 10 & 10 & 10 \\
\hline 01 & 01 & 01 & 01 & 01 & 01 \\
\hline 00 & 00 & 00 & 00 & 01 & 10 \\
\hline
\end{tabular}

Finally, the fourth and final category of logical systems is the class of non-complete and nonconsistent, or 'paranormal' systems. They correspond to von Wright's logic T'L. Paradoxically, these systems are not those which satisfy none but, on the contrary, all the four clauses (1) - (2) of PB. The paranormality-forming operators of acceptance admit the two 'bilateral' values $B=11$ and $N=00$ and are reduced to one single case: $\left[\mathrm{A}_{15}\right]$.

\begin{tabular}{|c|c|}
\hline$[p]$ & {$\left[\mathrm{A}_{15}\right] p$} \\
\hline 11 & 00 \\
\hline 10 & 10 \\
\hline 01 & 01 \\
\hline 00 & 11 \\
\hline
\end{tabular}

The above results partially agree with the classification proposed by Woleński for the different attitudes towards PB and Suszko's Thesis, which consists in dividing any language L into two and only two classes of logical values. While we recognize that there are different ways of disagreeing with PB, we are not following the same classification criteria. According to Woleński, the disagreement relates to 'Bivalentists', the 'Pseudobivalentists', and the 'Antibivalentists':

The Bivalentists accept PB (the conjunction of (1) and (2)), but they differ as far the matter concerns whether the bi-division of $\mathrm{L}$ suffices for constructing logic. The Pseudobivalentists accept either the metalogical tertium non datur (1) or the metalogical principle of non-contradiction (2) and take the bi-division as sufficient or not. The Antibivalentists accept neutralities or dialetheias and deny that the bi-division adequately displays the basis of logic [34, p. 105.].

From a constructive point of view, Woleński's Bivalentists 'are these 'Semi-bivalentists' who form classical, that is to say, complete and consistent judgments; the Pseudo-bivalentists are these 'Semibivalentists' who form paracomplete or paraconsistent judgments; and the Antibivalentists are, paradoxically, the 'complete' Bivalentists who form paranormal judgments by admitting the four clauses of PB. This paradoxical result comes from our 'constructive' or analytical reading of bivalence, while Woleński [34] does not divide the clauses of consistency and completeness into two logically independent clauses. In all cases, the bi-division required by Suszko's Thesis never allows the construction of non-classical logic systems in the framework of $\mathrm{AR}_{4[\mathrm{O} i]}$.

Our pragmatic reconstruction of logical systems hopes to draw attention to four main points.

Firstly, 'classical' logic and 'bivalent logic' are not synonymous expressions from our pragmatic point of view. The so-called 'classical' logic was constructed by 'semi-bivalent' systems, insofar as it does not satisfy the four PB clauses but only two of them (as opposed to the 'paranormal' logic which, paradoxically, obeys all clauses of PB but is not a 'classical' system).

Secondly, there are strictly speaking no 'classical', 'paracomplete' or 'paraconsistent' negations. It is shown above and in Schang [25] that it is not the two sentential negations (Boolean and Morganian) but the acceptance operators that distinguish the classes of theorems from classical and 
non-classical systems. In other words, the 'classical' agent is not distinguished from other agents by his particular use of negation but, rather, by his attitude towards PB or what justifies a statement of truth.

Thirdly, the illocutionary interpretation of judgments provides a certain answer to the sea-battle problem, presented in the Chapter IX of Aristotle's De Interpretatione and studied a length by Łukasiewicz. To the question of how to validate PEM,

PEM Every sentence $p$ or its negation $\sim p$ is true,

without admitting the completeness clause of $\mathrm{PB}$,

$$
\text { Every sentence is true or false, }
$$

Łukasiewicz [11] proposed a trivalent logic which rejects PB but is not able to validate PEM. Is it only possible, and on what condition in $\mathrm{AR}_{4[\mathrm{O} i]}$ ? The problem essentially relates to the relation between PEM and its metalogical version of tertium non datur, expressed by the completeness clause (2) of PB. If the two principles are independent from each other, it means that it is possible to admit one without the other. In accordance with the formation rules of judgments and the translation of PEM and (2) in $\mathrm{AR}_{4[\mathrm{O} i]}$ :

$\left(\mathrm{PEM}^{\prime}\right) \quad\left[\mathrm{A}_{i}\right]\left(p \vee\left[\mathrm{N}_{15}\right] p\right)$

$$
\left[\mathrm{A}_{\mathrm{i}}\right] p \vee\left[\mathrm{A}_{i}\right]\left[\mathrm{N}_{15}\right] p
$$

validating PEM without BV consists in finding an interpretation of $\left[\mathrm{A}_{i}\right]$ such that the following thesis is not valid:

$$
\left(\mathrm{PEM}^{\prime}\right) \rightarrow\left(2^{\prime}\right)
$$

The operator $\left[\mathrm{A}_{8}\right]$ seems to satisfy this request but requires an extension of Łukasiewicz's analysis to four-valuedness. By replacing sentential variables with their algebraic referents, we thus obtain the following proof of invalidity:

$$
\begin{aligned}
& {\left[\mathrm{A}_{8}\right] 11 \vee\left[\mathrm{N}_{15}\right] 11 } \rightarrow\left[\mathrm{A}_{8}\right] 11 \vee\left[\mathrm{A}_{8}\right] 00 \\
& {\left[\mathrm{~A}_{8}\right](11 \vee 00) } \rightarrow\left[\mathrm{A}_{8}\right] 11 \vee\left[\mathrm{A}_{8}\right] 00 \\
& {\left[\mathrm{~A}_{8}\right] 10 } \rightarrow 01 \vee 01 \\
& 10 \rightarrow 01 \\
& 01
\end{aligned}
$$

One can doubt, however, the philosophical insightfutlness of this result, beyond its purely formal meaning. Even if the paranormal situation of the antecedent may agree with the thesis of indeterminism, the problem, on the other hand, concerns the meaning of sentential negation: the proof above rests essentially on the use of Boolean negation, while the notion of falsehood included in the consequent PB results in a Morganian negation which modifies the above result of the proof. Another solution would be to admit bivalence by replacing the notion of falsehood with that of non-truth, so that the consequent PB would be replaced by $\mathrm{PB}^{\prime}$. Now such a formal 'solution' does not account for the sea-battle problem by reducing it to a trivial version. It therefore remains an open issue, especially regarding the meaning to be given to sentential negation: Morganian, in 'it is the case that the sea-battle 
will take place or will not take place'; or Boolean, in 'it is the case that the naval battle will take place or it is not the case that the sea-battle will take place'. ${ }^{13}$

Fourthly, the functional definition of the acceptance operators provides a new and completely abstract explanation of the concept of duality. Thus, for any operator $\left[\mathrm{A}_{i}\right]$ and all algebraic values $X, Y$ :

$$
\text { If }\left[\mathrm{A}_{i}\right] p: X \mapsto Y \text {, then } d\left(\left[\mathrm{~A}_{i}\right] p\right): \bar{X} \mapsto \bar{Y}
$$

Each of the paracomplete systems of $\mathrm{AR}_{4[\mathrm{O} i]}$ is the dual of a paraconsistent system, by this definition. Duality can also be interpreted by the relation of subalternation, within the framework of the theory of oppositions. It is this notion of duality that we will find again later on, with respect to the relationship between logic and scepticism. It will allow to see if there are other types of propositional attitudes than acceptance and rejection or if attitudes such as assertion, assumption and doubt are all reducible to the two pragmatic operators of $\mathrm{AR}_{4[\mathrm{O} i]}$.

\section{Logics of Attitudes}

If we accept the hypothesis that logic concerns the relationship between judgments, this implies that the speaker commits to the truth of certain sentences and also accepts the logical consequences of this commitment. However, the preceding discussion on bivalence and the plurality of agents represented in $\mathrm{AR}_{4[\mathrm{O} i]}$ assumes that these agents are multiple and that not only one rationality is assumed by all of these. Woleński draws a relevant formal lesson from this plurality, with respect to the redundant theory of truth and Tarski's T-scheme: "considerations about the T-scheme show that T-equivalences are no longer logical tautologies beyond propositional calculus" $[35, \text { p. 9. }]^{14}$

Von Wright confirms that the T-scheme does not hold universally

The equivalence $\mathrm{T} p \leftrightarrow p$ is well-known from discussions about the nature of truth. Its meaning is often expressed by saying that the phrase 'it is true that', when prefixed to a sentence, is otious or redundant. But this is true only if one accepts the laws (of excluded middle and of contradiction) of classical logic. In classical logic the phrase 'it is true that' is indeed redundant - and this explains why the truth operator is not needed in the object language of the classical calculus. But the classical calculus is only a special, limiting, case of truth-logic. In other truth-logics the truth-operator is not redundant [30, p. 325]. ${ }^{15}$

This is the obviously the case in the pluralist framework $\mathrm{AR}_{4[\mathrm{O} i]}$, where the $\mathrm{T}$-scheme may not be valid for some interpretations of $\left[\mathrm{A}_{i}\right] .{ }^{19}$

Faced with a plurality of formal truth-logics, Woleński [30], [32] investigates the philosophical forms of this plurality. He goes on discussing its traditional expressions in the history of philosophy, especially through the distinction established by Sextus Empiricus between three patterns of rationality: dogmatism, academicism, and scepticism. The latter seems to pose an enigma for logic: Does the sceptical agent recognize some particular cases of truth, and what logic can he admit if he does not recognize any? Let us take a look at Woleński's analysis, in order to see what we can learn from it within our pragmatic logic.

This analysis is based on three components: a precise definition of the three philosophical schools mentioned above, based on the commentary by Arne Naess; a representation of the logical relationships between the three types of agents which result from it, in the form of a hexagon of logical oppositions; an explanation of sceptical logic 'in the form of a dual consequence'.

The main trouble comes from the meaning of the original text by Sextus Empiricus. According to the author, each of the three philosophical schools studied expresses a distinct epistemic attitude: 
dogmatism asserts that the truth is discoverable; academicism asserts that the truth is not discoverable; the sceptic does not assert that the truth is discoverable, nor does he assert that the truth is not discoverable (he seeks the truth without finding it yet). We recognize here another triad of contraries between the three positions, and Woleński offers an exhaustive representation of epistemic attitudes in the form of a logical hexagon (DIA), ${ }^{16}$ isomorphic to the preceding hexagon of truth-values (S2).

The inclusive position $(\varepsilon)$ corresponds to general dogmatism and comes in two forms: $(\alpha)$ 'optimistic' dogmatism, expressed by academicism; $(\beta)$ 'pessimistic' dogmatism, expressed by academicism. The exclusive position $(\varphi)$ corresponds to scepticism, which rejects the positive assertion of the dogmatist and the negative assertion of the academician.

(DIA)

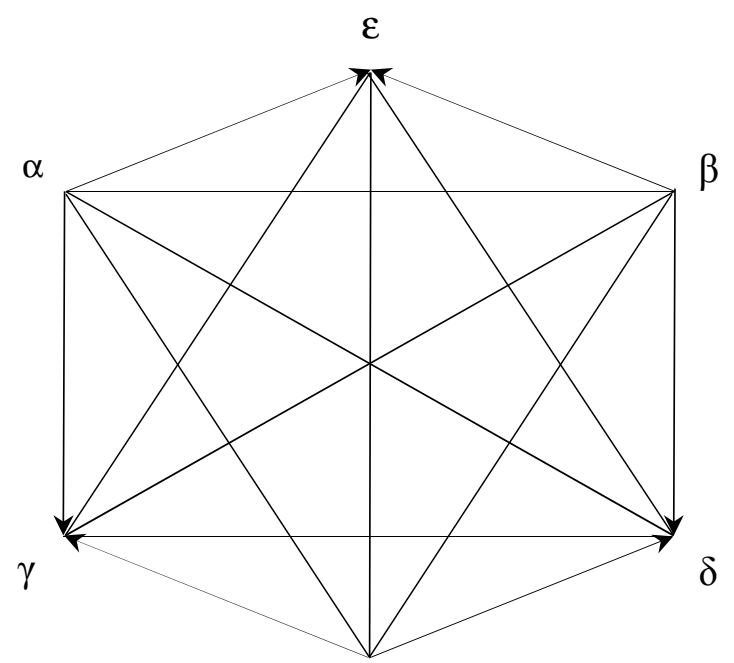

$\varphi$

The first logical difficulty comes from the meaning to be given to the indefinite expression 'the truth': is it any truth whatsoever, or some truth in particular? According to Woleński, only an existential interpretation of this definite article can restore the precise meaning of the academic position:

The dogmatist's view cannot be rendered by

(20) I assert that every truth is discoverable,

because it would make it impossible to state academism and scepticism adequately to their actual historical form. Assume that (20) is taken as proper for dogmatism. By our (DIA), the academician would say

(21) I assert that not every truth is discoverable (= I assert that at least one truth is not discoverable). However, this statement is too weak for the academician, because it does not exclude that possibly some truths are discoverable. Now the sceptic, under (20) and (21), must say

(22) I do not assert that every truth is discoverable and I do not assert that at least one truth is not discoverable.

This statement is too weak for the sceptic, because it ascribes to him the view that abstaining from assertions is restricted only to selected propositions belonging to a given K. Since the sceptical doubt is universal in $(K),(22)$ drops an essential part of scepticism. This, the dogmatist should be moderate in his epistemic ambitions in order to be fair to his competitors [33, p. 189.] 
This passage seems to express a half-truth. Woleński is right to say that the sceptic does not accept any particular truth according to the principle of isosthenia, so that there is no sufficient reason to assert $p$ or its negation $\sim p$. On the other hand, does the expression of sceptical attitude impose one and only one possible expression for the attitudes of dogmatism and scepticism? Woleński seems to think so. His reasoning proceeds as follows: if the dogmatist asserts that every truth is discoverable, then the academician asserts the contrary. What is this contrary? According to Naess, this is the assertion that at least one truth is not discoverable; however, this assertion does not correctly restore the attitude of the academician; therefore, the dogmatist's attitude must be reformulated accordingly and expressed as the assertion that at least one truth is discoverable. This reasoning is based on the idea that the triad of opposites $\alpha \beta \varphi$ of the hexagon (DIA) must be exhaustive ; that is to say, it must exhaust the entire space logic so that $\alpha \vee \beta \vee \varphi$ is a tautology.

At the same time, it is possible to express a greater number of epistemic attitudes than those expressed in (DIA). As shown by Englebretsen [5], this number depends on the logical structure of the expressions and the different ways of denying them. Starting from

(a) I assert that every truth is discoverable,

it is possible to express seven other different judgments on the basis of (a), modifying its logical form by the introduction of negations:

(b) I assert that every truth is not discoverable.

(c) I assert that not every truth is discoverable, i.e. I assert that at least one truth is not discoverable.

(d) I do not assert that every truth is discoverable.

(e) I assert that not every truth is not discoverable, i.e. I assert that at least one truth is discoverable.

(f) I do not assert that not every truth is discoverable.

(g) I do not assert that every truth is not discoverable.

(h) I do not assert that not every truth is not discoverable.

The logical space of the formulas (a) - (h) is more complex than the hexagon (DIA), due to the logical structure of its formulas. In (DIA), negation is restricted and applies only to the sentential content 'every truth is discoverable'. The assertive modality of judgment is never denied, while it is in (d), (f), $(\mathrm{g})$, and (h). By analogy with the alethic modalities of necessity and possibility, assertion can be considered as a 'strong' epistemic modality and its negation means the 'weak' modality of supposition. Scepticism denies positive and negative assertions, therefore the attitude of doubt that characterizes it is equivalent to an epistemic contingency. On the basis of this interpretation, we can reformulate the negative judgments as follows:

(d) I suppose that not every truth is discoverable, i.e. I suppose that at least one truth is not discoverable;

(f) I suppose that every truth is discoverable;

(g) I suppose that not every truth is not discoverable, i.e. I suppose that at least one truth is discoverable;

(h) I suppose that every truth is not discoverable.

The diagram (DIA) is therefore a mere fragment of this set of expressions in which $(\alpha)=(e),(\beta)=(b)$, and $(\varphi)=\sim(\mathrm{e}) \wedge \sim(\mathrm{b})=(\mathrm{h}) \wedge(\mathrm{g})$. 
The problem to follow is twofold: What are the logical relationships between the formulas of the extended structure (a) - (h)? Did Naess and Woleński provide a correct interpretation of the three epistemic attitudes of dogmatism, academicism, and scepticism?

To study the set of logical relationships, we may analyze the logical space of these formulas as a set of logically independent subsets, that is to say mutually exclusive and exhaustive. The result is a Partition Semantics, similar to the analysis, of FA proposed in section 1 and inspired by various works [4], [9], [24]. The hexagon (DIA) is limited to a logical space $\Sigma_{1}$ composed of three subspaces:

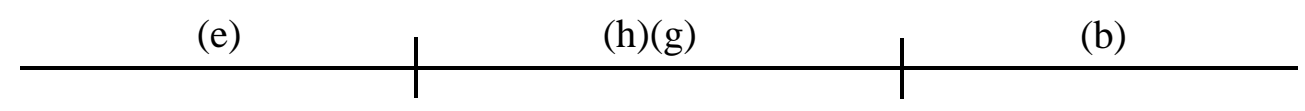

while the logical space $\Sigma_{2}$ of the expressions (a) - (h) includes six subspaces which are further partitions of the three previous ones:

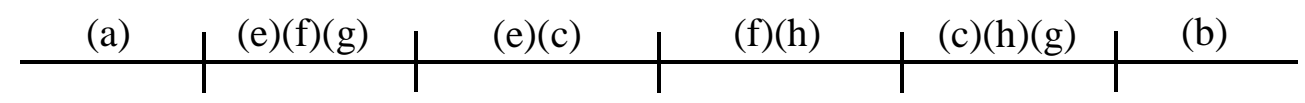

Each expression can then be interpreted as a set of occupied or unoccupied positions into a finite logical space. Let $\sigma$ be the function applying to each expression a corresponding value 1 or 0 in the different logical subspaces. This results in the following valuations for all of the formulas (a) - (h), to be identified by a characteristic bitstring (an ordered sequence of Boolean bits):

$\sigma(\mathrm{a})=100000, \sigma(\mathrm{b})=000001, \sigma(\mathrm{c})=001011, \sigma(\mathrm{d})=011111, \sigma(\mathrm{e})=111000, \sigma(\mathrm{f})=110100, \sigma(\mathrm{g})=$ $111110, \sigma(\mathrm{h})=110111$.

The above valuations above make it possible to define the set of logical relations by means of a Boolean calculus, composed of three bitstring operators: complementation, union, and intersection. Thus, for any bitstring $\sigma(x)=\left\langle\sigma_{1}(x), \ldots, \sigma_{n}(x)\right\rangle$ of length $n$ characterizing any abstract object $x:^{17}$

\section{Complementation}

$\sigma(\bar{x})=\left\langle\overline{\sigma_{1}(x)}, \ldots, \overline{\sigma_{n}(x)}\right\rangle$

\section{Union}

$\sigma(x) \cup \sigma(y)=\left\langle\sigma_{1}(x) \cup \sigma_{1}(y), \ldots, \sigma_{n}(x) \cup \sigma_{n}(y)\right\rangle$, with $1>0$ and $\sigma_{i}(x) \cup \sigma_{i}(y)=\max \left(\sigma_{i}(x), \sigma_{i}(y)\right)$.

\section{Intersection}

$\sigma(x) \cap \sigma(y)=\left\langle\sigma_{1}(x) \cap \sigma_{1}(y), \ldots, \sigma_{n}(x) \cap \sigma_{n}(y)\right\rangle$, with $1>0$ and $\sigma_{i}(x) \cap \sigma_{i}(y)=\min \left(\sigma_{i}(x), \sigma_{i}(y)\right)$.

Following the calculus of oppositions presented by Schang [24], complementation turns out to be a contradiction-forming operator. If the definitions of Naess and Woleński are correct, then:

- ('positive') dogmatism is (e), and its characteristic bitstring in $\Sigma_{2}$ is $\sigma(\mathrm{e})=111000$

- academism (or 'positive dogmatism') is (b), and its characteristic bitstring in $\Sigma_{2}$ is $\sigma(\mathrm{b})=$ 000001 
- scepticism is a negation of the two dogmatisms, therefore it corresponds to the formula

$\sim(\mathrm{e}) \wedge \sim(\mathrm{b})=(\mathrm{h}) \wedge(\mathrm{g})$ and its characteristic bitstring is $\sigma(\mathrm{h} \wedge \mathrm{g})=\overline{(111000)} \cap \overline{(000001)}=$ $(000111) \cap(111110)=000110$

The set (a) - (h) can be partially represented in the hexagon (DIA), knowing that it constitutes the fragment of a total set of $2^{8}=256$ possible formulas within $\Sigma_{2}$.

(DIA)

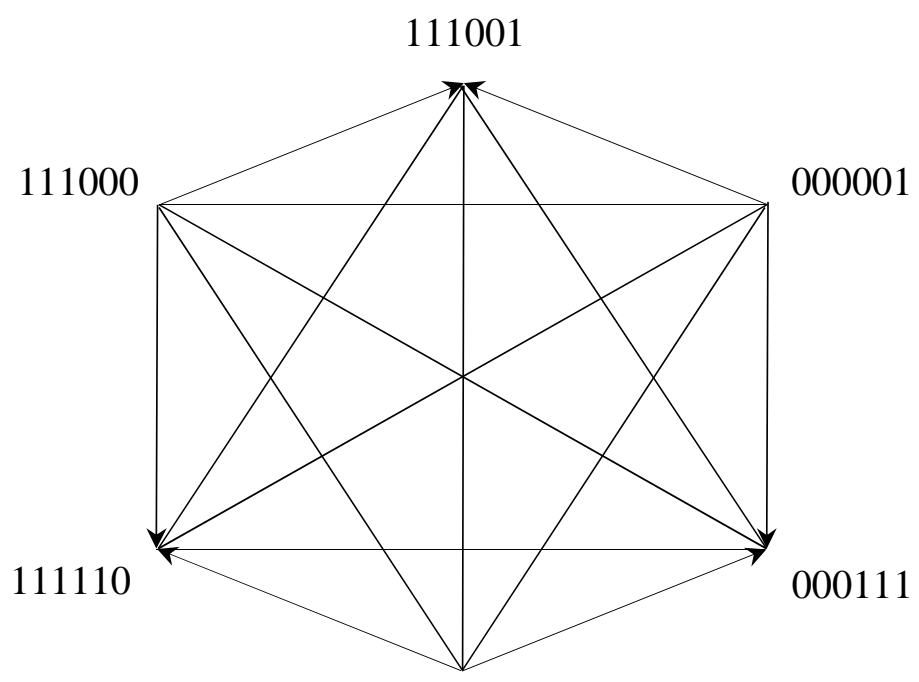

000110

The Boolean calculus also confirms the idea that dogmatism, academicism and scepticism constitute an exhaustive triangle of contraries: contraries, because their characteristic bitstrings never overlap with each other in $\Sigma_{2}$ and their intersection is therefore empty: $\alpha \wedge \beta \wedge \varphi=\perp$, i.e.

$$
\sigma(\alpha) \cap \sigma(\beta) \cap \sigma(\varphi)=111000 \cap 000001 \cap 000110=000000
$$

exhaustive, because the union of the three epistemic attitudes occupies the entire logical space such that $\alpha \vee \beta \vee \varphi=\mathrm{T}$, that is to say,

$$
\sigma(\alpha) \cup \sigma(\beta) \cup \sigma(\varphi)=111000 \cup 000001 \cup 000110=111111 .
$$

This partition semantics can also be applied to von Wright's truth-logics, based on the logical space $\Sigma_{3}$ which characterizes the operators $\mathrm{T}, \mathrm{F}$, and $\mathrm{T}^{\prime} . \Sigma_{3}$ turns out to be isomorphic to $\Sigma_{1}$, since $\Sigma_{3}$ also includes three subspaces mentioned in von Wright $[29,30]$ :

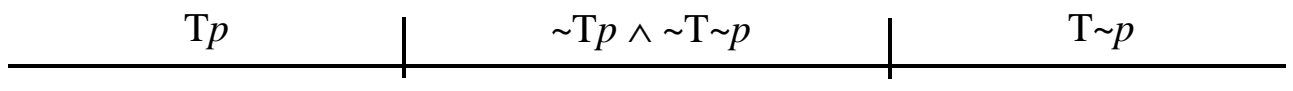

The result is a set of formulas characterized by bitstrings of length $n=3$, namely:

$\sigma(\mathrm{T} p)=100 ; \sigma(\sim \mathrm{T} p \wedge \sim \mathrm{T} \sim p)=010 ; \sigma(\mathrm{F} p)=\sigma(\mathrm{T} \sim p)=001 ; \sigma\left(\mathrm{T}^{\prime} p\right)=\sigma(\sim \mathrm{T} \sim p)=\overline{\sigma(\mathrm{T} \sim p)}=110 ;$ $\sigma\left(\mathrm{T}^{\prime} \sim p\right)=\sigma(\sim \mathrm{T} p)=\overline{\sigma(\mathrm{T} p)}=011 ; \sigma(\mathrm{T} p \vee \mathrm{F} p)=100 \cup 001=101, \sigma(\sim \mathrm{T} p \wedge \sim \mathrm{F} p)=011 \cap 110=010$. 
These valuations match with the logical hexagon (S2) of Woleński [34]:

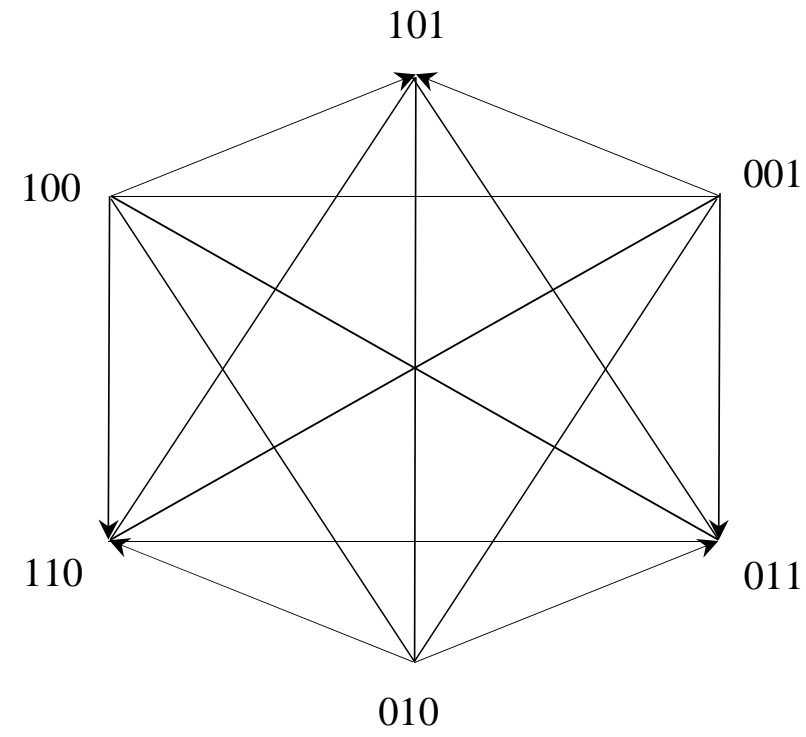

We can see here that the two non-unilateral truth values, $B$ and $N$, confirm what von Wright [29], [30] explained by his metaphor of the transition zone between dry and rainy weather: these are only two ways of expressing the same situation, that is to say, the same logical subspace in $\Sigma_{3}$.

The proof runs as follows, which consists in showing that the two metalogical operators B and $\mathrm{N}$ have the same characteristic bitstring:

$$
\begin{gathered}
\mathrm{B} p=\mathrm{T}^{\prime} p \& \mathrm{~T}^{\prime} \sim p, \text { so } \sigma(\mathrm{B} p)=110 \cap 011=010 \\
\mathrm{~Np}=\sim \mathrm{Tp} \& \sim \mathrm{T} \sim p, \text { so } \sigma(\mathrm{N} p)=011 \cap 110=010
\end{gathered}
$$

$B$ and $N$ say 'the same thing', whether in elementary terms of 'strong' or 'liberal' truth. The same conclusion can be reached within $\mathrm{AR}_{4[\mathrm{O} i]}$, in order to explain the distinction between the four categories of logical systems according to their interpretation of truth: 'paracomplete' systems give to it a 'strong' epistemic meaning, such that ' $\mathrm{T} p$ ' means ' $p$ is provable' or 'there is conclusive evidence in favor of $p$ '; 'paraconsistent' systems give a 'liberal' (or 'weak') epistemic meaning, such that ' $\mathrm{T} p$ ' means ' $p$ is justifiable' or 'there is reason to believe that $p$ (is the case)'; 'normal' (or 'classical') systems give an ontological meaning, such that ' $\mathrm{T} p$ ' means 'it is a fact (or it is) that $p$ '; ${ }^{18}$ the paranormal system, finally, combines the three previous interpretations and this explains why no theorem is valid in this system endowed with an absolutely free interpretation.

We come back now to the problem of Naess and Woleński.

What should be the correct interpretation of the epistemic attitude of scepticism? This seems to correspond to the operator $\left[\mathrm{A}_{5}\right]$ of $\mathrm{AR}_{4[\mathrm{O} i]}$, due to its two characteristic partial functions: the first mapping, $T \mapsto \bar{F}$, means that the existence of an argument for $p$ justifies the rejection of its falsehood; the second mapping, $F \mapsto \bar{T}$, means that the existence of an argument against $p$ justifies the rejection of its truth. The values of the domain therefore represent available data, while the values of the counterdomain express the judgment of the speaker determined by such data. 
Does the sceptical agent reject the truth of at least one proposition, or the truth of any proposition in the sense of a set of sentences $\mathrm{K}$ ? Woleński explained that only the first interpretation does justice to the contrary attitudes of dogmatism and academism; now we have shown that there are other opposite epistemic attitudes among the expressions (a) - (h), so that nothing seems to prevent the dogmatist from being even more radically opposed to the academician: the first is likely to assert that all truth is knowable, while the second would continue to think that no truth is knowable. The logical question is to ask whether or not dogmatists, academics and sceptics should constitute a set of epistemic attitudes not only exclusive but also, and above all, exhaustive. Although Gödel's second theorem of incompleteness gives a strong argument in favor of the interpretation of Naess and Woleński, it is possible to conceive of other more or less radical epistemic attitudes in relation to the three models cited and according to the meaning attributed to the concept of 'truth'.

Examples of seemingly 'irrational' epistemic attitudes come in particular from Indian philosophies, including the Jain theory of anekantavada or saptabhangi (theory of non-unilateral judgments) and the catuskoti (Tetralemma) of the Madhyamika or 'Middle Way' school. ${ }^{19}$ These two philosophical stances seem illogical because one seems to accept (the truth of) any sentence while the second would reject them all. In other words, the Jain agent asserts everything and embodies the expression (a), while the Madhyamaka agent asserts nothing. We will limit the examination of this possibility to situations of first-order beliefs, that is to say, to epistemic attitudes bearing on a sentential content and not on themselves (de se beliefs). Is it possible to believe the truth of any sentence? This seems to be the case of the sceptic, insofar as he opposes the 'positive' dogmatist who asserts at least one sentence. But since he also opposes the academician by not asserting the falsity of any statement, the sceptic therefore recognizes the truth or falsity of no statement. This amounts to a 'non-bivalent' situation in which rejecting the truth of a sentence does not imply asserting its negation, i.e. its falsehood. Although the logic $\mathrm{AR}_{[\mathrm{A} 5]}$ seems to account for this sort of agent, its characteristic matrix does not, however, prevent the assertion of a sentence whenever its assigned truth-value is 'unilateral'.

One can conceive the logic of the sceptic in two ways: either as an attitude of material rejection, or as an attitude of formal rejection. In the first case, the assertion of a sentence is formally possible but materially impossible, due to the epistemic inability of the sceptical agent to meet the criteria of justification for any sentence. This amounts to making a sort of truncation of the matrices characterizing the sceptic in $\mathrm{AR}_{4[\mathrm{~A} 5]}$, such as

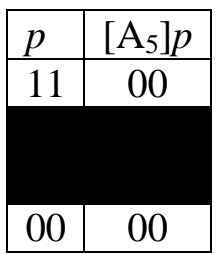

In the second case, it is formally impossible to assert anything due to the ontological inability of any sentence to meet the criteria of 'strict' truth. This amounts to performing a truncation in the field of truth-values, such that the domain of the sceptic eliminates all assertion and is compelled to interpret any sentence in $\mathrm{V}_{1}=N=\{00\}$. This situation is mathematically possible, and von Wright mentions it as one of the 16 'truth-logics' resulting from the powerset of the four initial values $B=11, T=10, F=$ $01, N=00$ :

There are in all 16 different ways in which one can "permit" or "forbid" some or several of the four cases. (We then include the two extreme cases of permitting all four and permitting none of them respectively.) 
These 16 selections answer to 16 different 'truth-logics'. Not all of them seem to be of interest and some of them, moreover, would seem to be identical with one another. [30, p. 314.]

The logic of the sceptic would correspond in this perspective to all of the sentences interpreted in the univalent domain $\{N\}=\{00\}$, indicated in red here below:

$$
\begin{gathered}
\operatorname{Card}\left(\mathrm{V}_{0}\right)=1=\{\varnothing\} \\
\operatorname{Card}\left(\mathrm{V}_{1}\right)=4=\{\{11\},\{10\},\{01\},\{00\}\} \\
\operatorname{Card}\left(\mathrm{V}_{2}\right)=6=\{\{11,10\},\{11,01\},\{11,00\},\{10,01\},\{10,00\},\{01,00\}\} \\
\operatorname{Card}\left(\mathrm{V}_{3}\right)=4=\{\{11,10,01\},\{11,10,00\},\{11,01,00\},\{10,01,00\}\} \\
\operatorname{Card}\left(\mathrm{V}_{4}\right)=1=\{11,10,01,00\}
\end{gathered}
$$

As for the epistemic attitude of the Jain, it would correspond to the opposite case (indicated in blue, here above) in which any statement is interpreted within the one-valued domain $\{B\}=\{11\}$. A reason for admitting this formal truncation is given by the internalist account of epistemic attitudes in Schang [19], [20], [22]: from his own point of view, the Jain attributes to the concept of truth a 'conventional' meaning (samvrti-satya) such that the slightest reason to accept a sentence is sufficient, while the Madhyamakas give to it an 'absolute' meaning (paramartha-satya) such that no reason is sufficient to accept any sentence. At the same time, an externalist account of epistemic attitudes modifies the domain of valuation of the Jain: his seven conceivable judgments consists in an exhaustive combination of the different kinds of epistemic attitudes which may be either normal and paraconsistent $(v(p) \in\{10,01,00\})$ or normal and paraconsistent $(v(p) \in\{11,10,01\}){ }^{20}$

Admitting such explanations seems essential to prevent the slightest case of assertion. The distinction between assertion and supposition may partially account for these radical epistemic attitudes: the Jain does not assert anything and supposes everything, so that his attitude is more akin to eclecticism than optimistic dogmatism; the sceptic asserts nothing and rejects everything, because his criterion of justification is so high that the truth of any sentence must be absolute. The logical effect of these attitudes is such that they cancel out the possibility of a bivalent domain, insofar as any truthvalue is designated for the Jain and not designated for the Madhyamaka. The bi-partition required for the construction of a consequence relation is therefore impossible, and any sentence then turns out logically true or logically false. It is not this path of one-valuedness that Woleński followed to analyze the logic of the skeptic, to whom he attributes a non-assertive and logical behavior at the same time. One way to maintain bivalence consists in replacing the notion of traditional consequence $C n$ by a dual consequence $d C n$, in which consequence does not preserve the truth of sentences but their falsity. Woleński explains the logic of the skeptic in that way, through the attitude of rejection. For all statements A,B:

If $A$ is rejected and $B$ is a dual consequence of $A$, then $B$ is also rejected. ${ }^{21}$

Let us note that, from a sceptical point of view, the concept of dual consequence should be synonymous with preserving untruth rather than falsehood (since the falsity of $p$ entails the truth of $\sim p$ ). Now the sceptical agent of Naess and Woleński seems to admit classical consequence and still make sense of the attitude of assertion after all. Woleński explains this point as follows:

Many things concerning rejection can be of course expressed by $\mathrm{Cn}$ and negation. For example, the modus tollens leads from asserting $A \Rightarrow B$ and asserting $\sim B$ (= rejecting $B$ ) to rejecting $A$ (= asserting not- $A$ ). However, the sceptic does not like the assertion game, 
even in a mixed form, and certainly he prefers the language that does not commit him to assertion [33, p. 192.]

Does the sceptic take dual consequence to be a mere alternative language game that is equivalent to the assertive language game? It all depends on the interpretation of his attitude towards sentence and the concept of truth. Woleński's version is more 'liberal' than ours, if radical scepticism means that one can attribute the truth to no sentence whatsoever. The dual consequence Woleński deals with is distinct from the traditional relation of consequence, but both are still interchangeable and the discourse of the sceptic does still make sense for a bivalent agent. From our point of view, it is the epistemic attitude $\left[\mathrm{O}_{i}\right]$ of the sceptic which is dual with that of the Bivalentists: rejection is untranslatable in terms of assertion, and the discourse of the sceptic is therefore a language game which is meaningless for a bivalent agent. No wonder if it is so difficult to construct a logic characterizing this agent, and the same holds for other agents such as Parmenides, Hegel, or Bradley.

\section{Partition Semantics for Non-Suszkian Logics}

It is not difficult to construct a logic which does not subscribe to the 'weak' version of PB, when the truth-values are algebraic values reducible to Suszko's logical values. On the other hand, it is much more difficult, if not impossible, to conceive of a logic that does not subscribe to the 'strong' version of $\left(\mathrm{PB}^{\prime}\right)$ : can we say of a statement that it is designated and not-designated at the same time? If a sentence is true-and-false, it is designated and is not undesignated. If a sentence is neither-true-nor-false, it is undesignated and is not designated. The various responses to Suszko's Thesis, (including [6,12]) did not refute this thesis but advanced alternative kinds of consequence (preserving either falsehood, or untruth). Suszko's Thesis is therefore not 'false' or inconsistent, but it may appear less 'insightful' in the sense that the Tarskian consequence would not be sufficient to understand rationality in a more comprehensive way.

A criterion of insightfulness was proposed by Woleński, in order to show the philosophical irrelevance of the coherence theory of truth: "If a theory is obscure, it should be abandoned; if it does not satisfy its promises, it should also be abandoned, and the same holds for a redundant theory. Since the coherence theory is obscure or it does not satisfy own promises or it is redundant, it should be abandoned" [32, p. 44.] Just as there can be several interpretations of logical principles and epistemic attitudes, Woleński also distinguishes two versions of the coherence theory of truth: a 'mixed' version, which maintains the existence of a true sentence corresponding to a fact while defining the truth of the other sentence in terms of coherence (if ' $p$ ' is held true in the sense of truth as correspondence, then the disjunction ' $p \vee q$ ' is true because it is coherent with respect to $p$ ); a 'pure' or 'Bradleyian' version (with reference to its author, Francis Herbert Bradley), by virtue of which it is a whole system of sentences $\mathrm{S}$ which is held true and not the sentences of S. Woleński criticizes this 'pure' definition of truth as coherence because of one main logical defect: the failure of 'down'-compactness, which is the converse of the compactness property and which Woleński defines [32, p. 46] as follows:

\section{If $\mathrm{X}$ is a set of propositions and every finite subset of $\mathrm{X}$ is true, then $\mathrm{X}$ is also true. ${ }^{22}$}

The failure of compactness in the coherence theory of truth is due to the holistic nature of the concept of truth: it is impossible to assign truth to single sentences of S, hence their truth is only 'partial' in the sense that they depend on the truth of all the other sentences of the system. Now this holism is more radical than the holism of the so-called Duhem-Quine thesis, in that it responds to a 'pure' theory of coherence whose meaning is of an ontological order; in contrast, Quine's truth as coherence is a holism of justification, rather than dealing with truth as it stands. Woleński quotes Russell, the main opponent 
of Bradley's idealism, according to which his doctrine seems obscure because it obeys some 'logic other than ours'. 23

The alternative is therefore the following, which can be depicted as Woleński's test of insightfulness: either a philosophical theory makes sense, and there is a logic able to explain this theory; or there is no such logic, and the theory does not make sense (it must be rejected, accordingly). It is notably this absence of clearly defined 'logic' which seems to justify the rejection of philosophical theories such as Bradley's therory truth as pure coherence, but also Parmenides' theory of being, Hegel's self-difference (inspired by Heraclitus), or even Heidegger's 'nihilating nothing'. Two questions arise here: Is the 'other logic' Russell was talking about compatible with the standards of modern logic, based on the fundamental relation of consequence? Can a theory be called 'logical' if it does not embed or include any consequence relation? We have seen so far that the plurality of modern logical systems rests on a certain version of logical pluralism, according to which the difference between systems lies in their disagreement about what 'being the case' means. ${ }^{24}$

Now the 'logics' of Bradley, Hegel or Heidegger seem to require more than a pluralism of truth, that is to say, a variety of definitions of the concept of truth within one and the same set-theoretical model (including the 'strict' and 'liberal' truths of von Wright [29], [30]; they seem to require a pluralism of ontology, i.e. the construction of models alternative to the mainstream model theory and incompatible with the formal semantics exposed thus far.

Partition Semantics, previously exposed in the analysis of epistemic attitudes, may be able to make sense of some of the "linguistic extravagances" 25 for which it seems impossible to construct one's own logic. Two case studies could appear as cases of 'non-Suszkian logics', i.e. rational systems in which the 'strong' principle of bivalence PB' does not hold: dialectical synthesis, and nothingness.

Several attempts to formalize the Hegelian dialectic have been proposed so far, including da Costa [3] and Rogowski [15]. ${ }^{26}$ In the former's system $\mathrm{C}_{0}-\mathrm{C}_{\omega}$, the concept of antinomy is rendered by a 'partial' negation whose applications validate or invalidate PC depending on the structural complexity of the sentences. In the latter's logic of change, a domain of four truth-values is proposed to make sense of the process of 'becoming'. This domain includes 'unilateral' truth-values (the true: 'it is the case only', and the false: 'it is not the case only') and 'non-unilateral' (sub-truth: 'it begins to be the case that', and sub-falsehood: 'it ceases to be the case that'), in order to explain the transition from being to non-being. This logical system partitions the concepts of being and non-being, in the sense that it attempts to explain this continuous transition between these two states in terms of discrete truthvalues. This passage takes place through a cyclical negation, which turns a 'unilateral' state into a 'nonunilateral' state (and vice versa). ${ }^{27}$ However, this system does not seem able to explain the process of dialectical synthesis: it always rests on the concepts of being and non-being, since it explains the concept of becoming as a transition between these two basic states or being and not-being.

A more 'radical' explanation would be to proceed in the reverse sense, without presupposing states and conceiving of being and not being as the results of the process of dialectical synthesis. A model of this kind is proposed in Schang [25], accounting both Bradley's truth as coherence and Hegel's sursumptive' negation. ${ }^{28}$ Let $x$ be a kind of initial object, the Absolute, which exhausts the logical space and whose truth-value is the True. The synthesis process is to be interpreted as an object constructor, by successively partitioning this initial exhaustive object into different parts that still 'participate' in it, in the light of the following 'tiered' model: 


\section{Level 1}

thesis

$T$

antithesis

$\bar{T}$

synthesis

$T \bar{T}$

\begin{tabular}{l|l}
\multicolumn{2}{c}{$x$} \\
\hline$x_{1}$ & $x_{2}$ \\
\hline
\end{tabular}

\section{Level 2}

thesis

$$
\frac{T \bar{T}}{T \bar{T}}
$$

antithesis

synthesis

$$
T \bar{T} \overline{T \bar{T}}
$$

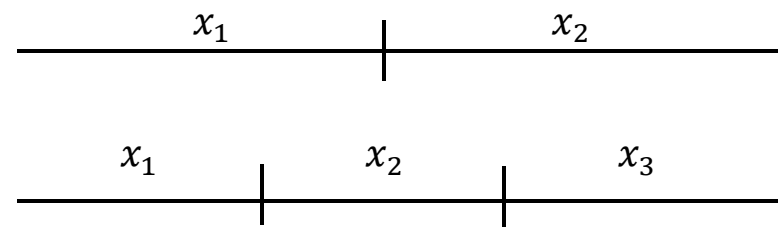

\section{Level 3}

$\begin{array}{ll}\text { thesis } & \frac{T \bar{T} \overline{T \bar{T}}}{T \bar{T} \overline{T \bar{T}}} \\ \text { antithesis } & T \bar{T} \overline{T \bar{T}} \overline{T \bar{T} \overline{T \bar{T}}}\end{array}$
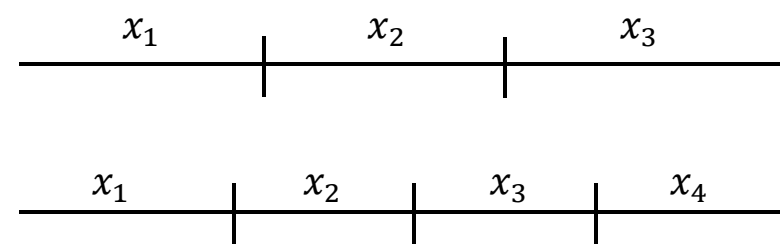

The initial being, $T$, is preserved hereby in each of subsequent states and results from a construction process identical to that of algebraic truth-values: the 'false' $F=\bar{T}$ corresponds to the antithesis of Level 1; the 'true-and-false' corresponds to the synthesis of Level 1, etc. This model is able to explain the meaning of metalogical negation applied to truth-values: it corresponds to the Hegelian negation or Aufhebung, which is often translated as a process of 'changing-by-preserving' and which escapes the principle of subsumption with judgments like ' $\mathrm{S}$ is $\mathrm{P}$ ' and ' $\mathrm{S}$ is not $\mathrm{P}$ '. Hegelian negation thus produces a change by the antithesis, but it guarantees the preservation of the original truth through synthesis. If this model gives meaning to Hegel's dialectic, it shows above all that the Hegelian negation is not an operator applied into a preestablished domain but, rather, a truth-value constructor. ${ }^{29}$ The same can be said of Heidegger's 'nihilation', which is also not a sentential negation but consists in rejecting a characteristic property of any object. In partition semantics, this means that the 'nihilation' process works like a subtraction operator that decreases the number of bits 1 of the bitstring characterizing an object. $^{30}$

Partition Semantics may also make sense of Bradley's holistic theory of truth as coherence, as well as to the concept of 'nothingness'. If the Hegelian dialectic explains the construction of an ontology as an increasing partition of one initial unique model into an increasing number of particular objects, the final set of constructed objects corresponds to Bradley's 'total' or 'absolute' truth T, and each singular object constitutes a 'partial' truth inseparable from T. Conversely, the concept of 'nothingness' designates that which is nothing and cannot be predicated of any object. The length of the bitstring $\sigma(x)$ characterizing any object $x$ makes it possible to distinguish the concepts of relative and absolute nothingness: 'relative nothingness' is an 'object' $x$ such that $\sigma(x)=\perp$ with a number of finite bits, while absolute nothingness would be characterized by a logically equivalent bitstring but whose number of bits is infinite. This distinction is also found in the constructive process of algebraic truth-values: in a bivalent value domain $2^{n}=2^{1}=2$, the 'false' corresponds to the empty set of 'non- 
true'; in a domain of quadrivalent values $2^{n}=2^{2}=4$, it is the 'neither-true-nor-false' which corresponds to the empty set while the 'false' constitutes a proper element of the domain. ${ }^{31}$ As for nothingness, it would be this particular 'object' which would remain empty in all the successive domains of truthvalues.

Admitting these explanations of truth as coherence, of Hegelian dialectics and of nothingness supposes a certain dose of tolerance with regard to the notion of 'logic': with no relation of consequence, as a process of constructing formal ontologies. In a sense, the relation of consequence rests on a process of discrimination (of the 'true' logic and the 'false' logic) whose philosophical counterpart is the distinction between being and non-being. However, being and non-being presuppose an ontology of stable objects, i.e. substances. A 'Suszkian' logic presupposes in this sense the existence of substances which cannot be reduced to accidental properties, while a 'non-Suszkian' logic does not presuppose any ontology and consists in building models rather than ordering their preexisting components. Bradley's model is not a set of particular objects, but an absolute object that includes everything. Hegel's model includes an absolute object, from which all the particular objects are derived and which participate in it. In contrast to these special models, the logical model is an Aristotelian model: an 'object' is something, that is to say, a finite set of properties some of which are predicated or not and whose characteristic bitstrings are thus distinguished from any other object in the comprehensive model. We find in this explanation an echo of Aristotle's hylemorphism, according to which every object is a unique combination of form and matter. This 'mixed' ontology contrasts with that of Parmenides and Heraclitus: in the first, everything is a form at rest, so everything 'is' whereas 'becoming' does not make sense; in the second, everything is a matter in movement, so everything 'becomes' whereas 'being' does not make sense. ${ }^{32}$ These ontologies therefore involve 'radical' judgments of total acceptance and total rejection, and Partition Semantics is likely to explain what Russell called a logic 'different from ours'. These are non-Suszkian logics, so to speak.

\section{Conclusion: What are Truth-Values?}

We did not pretend to address here all of Professor Woleński's philosophical and logical writings. However, we hope to have followed the general method of analysis which he has developed so far and which could be depicted as formal philosophy: the use of formal tools for the understanding and elucidation of philosophical problems.

The problems discussed here were some logical principles of rationality: PC, PEM, and PB; epistemic attitudes: dogmatism, academism, and scepticism; philosophical theories, such as Bradley's 'pure' theory of truth as coherence and the concept of nothingness. A fundamental tool was used to organize our thoughts on these issues, namely: truth-value, and our main questioning concerned the nature of such an abstract 'object'. Is there a specific answer to this question? Any relativistic response risks reducing logical analysis to an exercise of formal hermeneutics in which the theorist always has a reason to argue and is never at fault. However, this is more or less the answer that we bring to the end of this article, through a certain interpretation of truth-values: these are the referents of sentences, in accordance with the first clause $\mathrm{FA}_{1}$ of FA; but these referents are not reduced to two 'logical' objects which are the true and the false, as opposed to the second clause $\mathrm{FA}_{2}$. Any response to this subject requires an explanation of the nature of this abstract object.

From the perspective of proof theory, a truth-value means the result of a proof and it does not make sense to assign it to a sentence out of the process of proof. From the perspective of model theory, a truth-value means that a corresponding sentence belongs to a model and it makes no sense to assign a truth-value to it outside any model. The intended referent is therefore either a proof or a membership relation. But it can be even more, if this 'abstract object' of truth-value may receive other formal interpretations. 
The partition semantics introduced hereby has attempted to widen the field of interpretations in this way, beyond Suszko's 'logical' values and Łukasiewicz's 'algebraic' values. For Suszko and for Łukasiewicz, truth-values designate classes of sentences that are accepted or rejected and characterize the relation of consequence within a formal logic; in Bradley's theory of truth as coherence or the Hegelian dialectic as we have reconstructed them, truth-values designate classes of objects that differ from the usual sentences of formal logic: it is the totality of sentences, in Bradley's theory; it is no sentence in particular but, rather, an individual object, in Hegel's dialectic. Our conclusion is that the limits of formal logic depend essentially on the meaning attributed to the concept of 'referent'. If truthvalues are considered by Frege as proper names, these proper names are very general and can vary in their cardinality: there are only two exclusive according to Frege and Suszko, while there can be more according to Łukasiewicz; there is an infinite number of inclusive ones, for Hegelian idealists (all included in the 'Great Fact', or the Absolute), while there is none for the Madhyamaka Buddhists. ${ }^{33}$ Suszko's situations are also 'truth values' in their own right, once we no longer consider a truth-value as a class intended solely to characterize a relation of consequence. There may be even further interpretations of logical values, such that still relate to the consequence but go beyond the sole area of assertive judgments. An exhaustive treatment of truth-values thus belongs to a broader formal theory of values, but the present paper wanted to stick to the former ones. ${ }^{34}$

The idea of many-valued logics is no 'madness', everything depends on the function assigned to the formal language that makes uses of these. Łukasiewicz's 'madness' may pe pushed even further, as we did hereby. Only Woleński's test of insightfulness can convince us that a theory is not crazy, as long as it is possible to construct an appropriate formal theory of meaning. A formal semantics of partitions purports to fulfill this requirement, just as the semantics of possible worlds did it with respect to the language of modalities.

\section{References}

1. Beall, J. C., and G. Restall. Logical Pluralism, Oxford: Oxford University Press, 2006.

2. Blanché, R. Les structures intellectuelles (Essai sur l'organisation systématique des concepts), Paris: Vrin, 1966.

3. da Costa, N. C. On the theory of inconsistent formal systems, Notre Dame Journal of Formal Logic 15, 1974, pp. 497-510.

4. Demey, L., and H. Smessaert. Combinatorial Bitstring Semantics for Arbitrary Logical Fragments, Journal of Philosophical Logic 47, 2018, pp. 325-363.

5. Englebretsen, G. Knowledge, Negation, and Incompatibility, Journal of Philosophy 66, 1969, pp. 580-585.

6. Frankowski, S. Formalization of a plausible inference, Bulletin of the Section of Logic 33, 2004, pp. 41-52.

7. Gardies, J.-L. La logique du temps, Paris, PUF, 1975.

8. Gauthier, Y. Hegel: introduction à une lecture critique, Québec: Presses de l'Université Laval, Coll. 'Logique de la science', 2010.

9. Lemanski, J, and F. Schang. A Bitstring Semantics for Calculus CL, Logica Universalis, forthcoming.

10. Łukasiewicz, J. On the Principle of Contradiction in Aristotle, Kraków: Polska Akademia Umiejętności, 1910.

11. Łukasiewicz, J. On Three-valued Logic, Ruch Filozoficzny 5, 1920, pp. 170-171.

12. Malinowski, G. Q-Consequence Operation, Reports on Mathematical Logic 24, pp. 49-59.

13. Piaget, J. Traité de logique (Essai de logique opératoire), Paris: Dunod (1st edition: 1949).

14. Priest, G. The Logic of the Catuskoti, Comparative Philosophy 1, 2010, pp. 32-54.

15. Rogowski, S. The Logical Sense of Hegel's Concept of Change and Movement, Studia Filozoficzne 
6, 1961, pp. 3-39.

16. Schang, F. A Plea for Epistemic Truth: Jaina logic from a Many-Valued Perspective, In A. Schumann (ed.), Logic in Religious Discourse, De Gruyter, 2010, pp. 54-83.

17. Schang, F. Negation and Dichotomy, In D. Łukasiewicz and R. Pouivet (eds.), Scientific Knowledge and Common Knowledge, Bydgoszcz: Epigram Publishing House/Kazimierz Wielki University Press, 2009, pp. 225-265.

18. Schang, F. Trois paralogismes épistémiques, une logique des énonciations, In P.-E. Bour, M. Rebuschi and L. Rollet (eds.), Construction. Festschrift for Gerhard Heinzmann, London: College Publications, 2010, pp. 407-416.

19. Schang, F. Two Indian Dialectical Logics: saptabhañgī and catuṣkoți, in A. Gupta and J. van Benthem (eds.), Studies in Logic: Logic and Philosophy Today 29, 2011, pp. 45-74.

20. Schang, F. A One-valued Logic for Non-One-Sidedness, International Journal of Jaina Studies (Online) 9 (1), 2013, pp. 1-25.

21. Schang, F. On Negating, In E. Dragalina-Chernaya (ed.), Ontology of Negativity, Moscow: Kanon, 2014, pp. 329-376.

22. Schang, F. Eastern Proto-logics, In J.-Y. Béziau, M. Chakraborty and S. Dutta (eds.), New Directions in Paraconsistent Logics, New Delhi: Springer Proceedings in Mathematics and Statistics, 2016, pp. 529-552.

23. Schang, F. From Aristotle's Oppositions to Aristotelian Oppositions, In V. Petroff (ed.), The Legacies of Aristotle as Constitutive Element of European Rationality, Proceedings of the Moscow International Conference on Aristotle. RAS Institute of Philosophy, October 17-19, 2016, Moscow: Aquilo Press, 2017, pp. 430-445.

24. Schang, F. End of the square?, South American Journal of Logic 4 (2), 2018, pp. 1-21.

25. Schang, F. A General Semantics for Logics of Affirmation and Negation, Journal of Applied Logics 2020, forthcoming.

26. Schang, F. Question-Answer Semantics, Revista de Filosofia Moderna e Contemporeâna, 8, 2020, pp. 73-102.

27. Suszko, R. The Fregean axiom and Polish mathematical logic in the 1920's, Studia Logica 36, 1977, pp. 377-380.

28. Turzynski, K. The Temporal Functors in the Directional Logic of Change of Rogowski - Some Results, Bulletin of the Section of Logic 19, 1990, pp. 30-32.

29. von Wright, G. H. Truth, Negation and Contradiction, Synthese 66, 1986, pp. 3-14.

30. von Wright, G. H. Truth-logics, Logique et Analyse 30, 1987, pp. 311-334.

31. Woleński, J. A Note on Scepticism, Kriterion 3, 1992, pp. 18-19.

32. Woleński, J. Against Truth as Coherence, Logic and Logical Philosophy 4, 1996, pp. 41-51.

33. Woleński, J. Scepticism and Logic, History and Philosophy of Logic 1, 1998, pp. 187-194.

34. Woleński, J. The Principle of Bivalence and Suszko's Thesis, Bulletin of the Section of Logic 38, 2009, pp. 99-110.

35. Woleński, J. An Abstract Approach to Bivalence, Logic and Logical Philosophy 23, 2014, pp. 3-15.

36. Woleński, J. Something, Nothing and Leibniz's Question, Negation in Logic and Metaphysics, Studies in Logic, Grammar and Rhetoric 54, 2018, pp. 175-190.

37. Woleński, J. Logical Ideas of Jan Łukasiewicz, Studia Humana 8, 2019, pp. 3-7.

38. Zaitsev, D., and Y. Shramko. Bi-facial Truth: a Case for Generalized Truth Values, Studia Logica 101, 2013, pp. 1299-1318. 


\section{Notes}

1. The two versions of bivalence are symbolized $\mathrm{PB}$ and $\mathrm{PB}^{\prime}$, in [34]. We will focus here on PB, i.e. the formulation of bivalence in terms of algebraic values.

2. Woleński points that, regarding the psychological interpretation of PC, "Eukasiewicz argues that the last understanding is irrelevant for logic, because it is an empirical fact that people assert contradictory assertions." [37, p. 4]. One might ask two questions about Łukasiewicz's intriguing position with respect to this psychological interpretation of PC. First, why does he believe that the existence of contradictory beliefs does not constitute a sound reason for invalidating PC? Second, are these contradictory beliefs held in the context of transparent or opaque discourse, that is, known or unbeknownst to doxastic agents? Our pragmatic interpretation of PC will take the existence of such contradictory beliefs seriously.

3. 'Sentence' and 'proposition' will be used interchangeably throughout the paper, as they only occur with an indicative use.

4. One could blame this example for confusing what is distinct in the theory of speech acts, namely: assertive acts, and declarative acts. The example of sentence on the metric convention could be considered an example of the latter, and thus show that this sentence is not a proposition. On the other hand, metaphysical propositions are indeed assertive acts and thus confirm Von Wright's view that there are propositions neither true nor false.

5. The author also sees in this liberal interpretation of truth a possible explanation for the process of 'synthesis' in Hegel's dialectic: "I suppose that it is something like that which happened in Dialectical Synthesis". We will return to this process later one, with respect to truth as coherence and nothingness. 6. 'Affirmation' and 'negation' are understood here as illocutionary forces, and not as the locutionary properties of a sentence or propositional content. To avoid confusion between these locutionary and illocutionary aspects, we will only use the phrases 'acceptance' and 'rejection' in the rest of this article. 7. One can also interpret these operators as functions which transform only certain truth-values and leave the others unchanged: $\left[\mathrm{A}_{1}\right]$ turns the true into non-false and leaves the false unchanged, for example. They are not 'total functions', in the sense given by Béziau in the Appendix of [35].

8. This means that $T$ constitutes the primary element in the construction of truth value domains: from $T$ comes the false, $F=\bar{T}$, then the other non-bivalent truth-values. We will return to this process of constructing truth values in order to try to shed light on Woleński's reflections on Bradleyian coherence and nothingness.

9. "Having a logic with $2^{n}$ logical values, we can always construct its extension with $2^{n+1}$ logical values" [34, p. 106].

10. The proof of identity of $\left[\mathrm{AN}_{i}\right]$ and $\left[\mathrm{NA}_{i}\right]$ is provided [25], as well as the redundant operator form of the classical assertion: $\left[\mathrm{AA}_{i}\right]=\left[\mathrm{NN}_{i}\right]$. It is also explained that the 'fusion' of operators is distinct from their composition or iteration, of form $[\mathrm{A}][\mathrm{N}] p$ (acceptance of rejection) and $[\mathrm{N}][\mathrm{A}] p$ (rejection of acceptance).

11. The details of this general framework will not appear in this paper, due to its irrelevance for the present issue; for a presentation of the syntax and semantics of $\mathrm{AR}_{4[\mathrm{O} i]}$, see [25]. The logical constants may be explained as follows in $\mathrm{AR}_{4[\mathrm{O} i]}$, for any arbitrary sentences $p, q$ such that their algebraic values are the ordered pairs $v(p)=\left(\mathrm{X}_{1}, \mathrm{Y}_{1}\right)$ and $v(q)=\left(\mathrm{X}_{2}, \mathrm{Y}_{2}\right)$. Thus: $v(p \wedge q)=\left(\max \left(\mathrm{X}_{1}, \mathrm{Y}_{1}\right), \min \left(\mathrm{X}_{2}, \mathrm{Y}_{2}\right)\right) ; v(p$ $\vee q)=\left(\min \left(\mathrm{X}_{1}, \mathrm{Y}_{1}\right), \max \left(\mathrm{X}_{2}, \mathrm{Y}_{2}\right)\right) ; v(p \rightarrow q)=\left(\max \left(\mathrm{X}_{2}, \mathrm{Y}_{2}\right), \min \left(\mathrm{X}_{1}, \mathrm{Y}_{2}\right)\right)$.

12. This formation rule means, recalling von Wright's truth-logics, that there are no 'mixed' formulas like $\left[\mathrm{O}_{i}\right] p \rightarrow p$ in $\mathrm{AR}_{4[\mathrm{O} i]}$. Indeed, the expression ' $\left[\mathrm{O}_{i}\right] p$ ' indicates a judgment whereas ' $p$ ' indicates a mere sentential content. The formula ' $\left[\mathrm{O}_{i}\right] p \rightarrow p$ ' is therefore an ill-formed sentence meaning something like 'If the door is closed, then closing the door'). It is because of this syntactic rule that the 
logical octagon proposed by [34] does not make sense in $\mathrm{AR}_{4[\mathrm{O} i]}$, since Woleński admits formulas of types $\mathrm{T} p \rightarrow p$ by admitting of sentential variables among its well-formed formulas.

13. Von Wright also states the equivalence of $\left(\mathrm{PEM}^{\prime}\right)$ and $\left(2^{\prime}\right)$, due to the Morganian behavior of negation in his paraconsistent truth-logics $\mathrm{T}^{\prime} \mathrm{L}$ and $\mathrm{T}$ " $\mathrm{L}$ : "Is $\mathrm{T}(p \vee \sim p)$ a tautology? The answer is No. It can, in fact, easily be shown that $\mathrm{T}(p \vee \sim p)$ is logically equivalent in (TL) with $\mathrm{T} p \vee \mathrm{T} \sim p$, i.e. with the Principle of Bivalence." [29, p. 10.]

14. The T-scheme is of form $\mathrm{T} p \leftrightarrow p$, which lies behind the 'deflationary' theory of truth and means that the semantic predicate of truth $\mathrm{T}$ adds nothing substantial to the meaning of the sentential content $p$.

15. Note that the translation of $\mathrm{T} p \rightarrow p$ in $\mathrm{AR}_{4[\mathrm{O} i]}$ is not $\left[\mathrm{A}_{i}\right] p \rightarrow p$, which is an ill-formed formula. Rather, it must be rephrased as $\left[\mathrm{A}_{i}\right]\left(\left[\mathrm{A}_{i}\right] p \rightarrow p\right)$, 'I accept that everything I accept has an evidence for it'. It turns out that this last formula does not hold with, e.g., [ $\left.\mathrm{A}_{8}\right]$. Indeed,

$\left[\mathrm{A}_{8}\right]\left(\left[\mathrm{A}_{8}\right] 11 \rightarrow 11\right)=\left[\mathrm{A}_{8}\right](00 \rightarrow 11)=\left[\mathrm{A}_{8}\right] 01=01$.

16. $\alpha=$ 'I assert that the truth is discoverable'; $\beta=$ 'I assert that the truth is not discoverable'; $\gamma$ : 'I do not assert that the truth is not discoverable'; $\delta=$ 'I do not assert that the truth is discoverable'; $\varepsilon=$ 'I assert that the truth is discoverable or I assert that the truth is not discoverable'; $\varphi=$ 'I do not assert that the truth is discoverable and I do not assert that the truth is not discoverable'.

17. This abstract object may be a sentence, but also a concept, or even an individual object. See e.g. [9] about the latter case.

18. Any confusion between the 'antirealist' (epistemic) and 'realist' (ontological) interpretations of $T$ risks producing paradoxical consequences if these are admitted within a single, single logical system, which is not the case in $\mathrm{AR}_{4[\mathrm{O} i]}$. This seems to be the case with the 'Fitch Paradox', whose conclusion is that a proposition is true if and only if it is known: $p \rightarrow \mathrm{K} p$. The 'paradoxical' consequence of this antirealistic definition of truth is indeed based on a 'mixed' formal language in which $p$ and $\mathrm{K} p$ belong to the same object language. A syntactic criticism of this paradox is formulated in [18], which consists in refusing any mixed formula as an ill-formed formula (thus blocking the initial premise of the paradox). Another anti-paradox strategy appears in the 'bi-facial' system [38], which consists in distinguishing two kinds of truth-values: ontological ( $T$ and $F$ ), and epistemic (1 and 0$)$.

19. See in particular [16], for a many-valued analysis of saptabhangi in either 7- or 15-valued domains. See also $[19,20]$ for a 1-valued (therefore non-Suszkian) analysis of saptabhangi and catuskoti.

20. The cardinal of the Jain seven judgments follows from combinations of different epistemic attitudes, which yields this general model of particular models or valuations: $\left\{\{10\},\{01\},\{11\},\{10,01\},\{10,11\},\{01,11\},\{10,01,11\}\right.$, in the normal and paraconsistent system $\mathbf{J}_{7 \mathrm{G}}$; $\left\{\{10\},\{01\},\{00\},\{10,01\},\{10,00\},\{01,00\},\{10,01,00\}\right.$, in the normal and paracomplete system $\mathbf{J}_{7 \mathrm{M}}$. Thus, there are $2^{3}=8-1$ possible ways of judging any sentence from a set of 3 single epistemic attitudes, the $8^{\text {th }}$ forbidden case being the one in which sentences are neither accepted nor rejected. We take this last situation to match with the Madhyamaka stance of 'silence' or peace of mind, such that the sentence is entertained without being judged at all. See [14] about this interpretation which seems to corresponds to the above special case $\{\varnothing\}$ of von Wright's 16 truth-logics.

21. For example, let $\mathrm{A}=p$ and $\mathrm{B}=p \wedge q$.

22. Woleński specifies that the principle of compactness trivially holds in the Bradley system, since this principle is expressed in the form of a conditional whose antecedent is false. It is only the converse of this principle that is awkward.

23. "The coherence-theory is generally advocated [...] in the connection with logic entirely different from ours." [32, p. 45.]

24. The pluralism of the criteria for assigning truth is defended in particular in [1]; it is opposed to Carnap's logical relativism, where the disagreement does not come from the meaning of truth but from the meaning of logical constants (regardless of their truth conditions). 
25. 'Perhaps Heidegger's and Sartre's linguistic extravancies, like 'nihilation' or 'neantization' well illustrate various troubles with the (absolute) Nothingness." [36, p. 187.]

26. For a discussion of Rogowski's logic of change, see especially [28] and also [7], [17]. This logic modifies the previous explanation given by von Wright [29], [30] about the drizzle, which he presented as a case of rain and no rain and which becomes hereby a case of 'sub-falsehood'.

27. This cyclical negation cannot be translated in $\mathrm{AR}_{4[\mathrm{O} i]}$, because it establishes between truth-values an ordering relation which does not correspond to any of the rejection operators $\left[\mathrm{N}_{i}\right]$.

28. The concept of 'sursumption' was created by Gauthier [8] to point out the idea that Hegel's being overhangs (and includes) contradictory qualities, as opposed to the principle of subsumption that rules contradictory (and exclusive) judgments of form ' $\mathrm{S}$ is $\mathrm{P}$ ' and ' $\mathrm{S}$ is not $\mathrm{P}$ '.

29. This operator is compared to the succession operator $\mathrm{S}$ of Peano's arithmetic such as $\mathrm{S}(n)=n+1$.

30. This operator may be viewed as a precedence operator $\mathrm{P}$ dual to $\mathrm{S}$, such as $\mathrm{S}(n)=n-1$.

31. The relativity of nothingness is evoked by Woleński with the example of the silent composition of John Cage, 4'33. Woleński poses the following question: "Let us assume that every year Cage would have written a piece of finite length, but always a minute longer than the present one. Would then the structure of, say, 6'33 be the same as that of 4'33?' [36, p. 187]. Our answer is No: the two compositions would have been different, due to the difference in length $n$ in their characteristic bitstrings.

32. The distinction between 'nothing', 'something' and 'everything' is explained in [23] as a difference between their respective bitstrings: 'something is some thing' and 'no thing is nothing' hold, whereas 'every thing is everything' does not.

33. The constructive process of truth-values that leads to various domains of valuation shows this increasing process of relative bitstrings, where every finite bitstring relates to a special kind of proper name: a Kripkean proper name, which behaves as a uniquely identifying expression.

34. 'Good' and 'wrong' may also occur as the referents of moral propositions, i.e. expressive speechacts by means of which Leo Strauss' Reductio at Hitlerum is rendered as a moral version of Modus Tollens. See Schang, F., "Moral Inferences" (draft) and "Political Oppositions" (talk to be delivered at the next $7^{\text {th }}$ World Congress on the Square of Opposition, Leuven, September 7-11, 2021). 